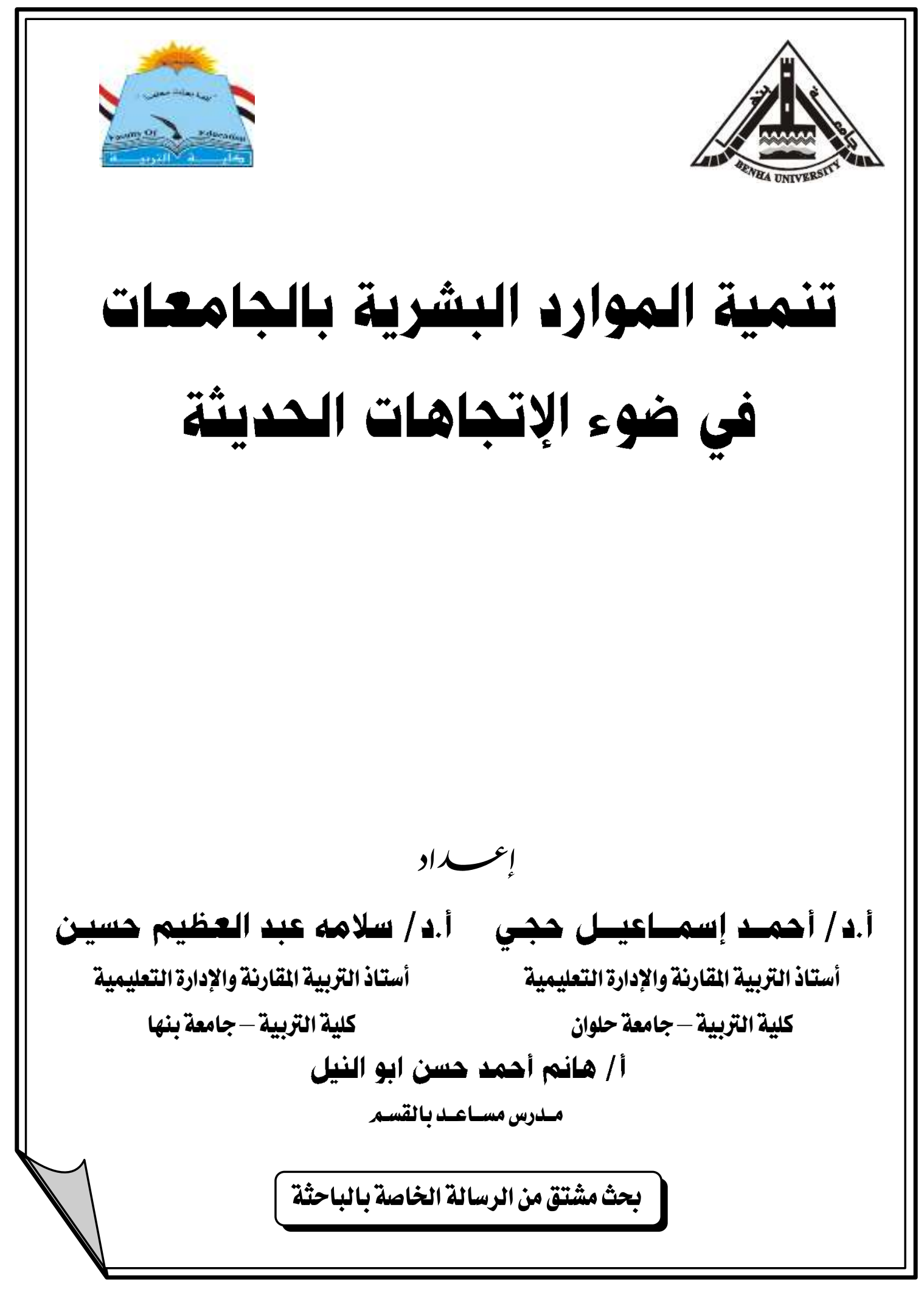




\section{تنمية المواره البشرية بالجامعات في ضوء الإتجاهات الحديثة}

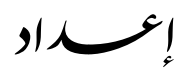

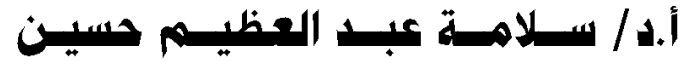

أستاذ التربية المقارنة والإدارة التعليمية

كلية التربية - جامعة بنها

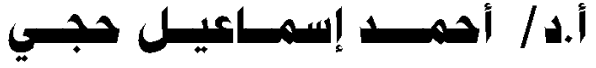

أستاذ التربية المقارنة والإدارة التعليمية كلية التربية - جامعة حلوان

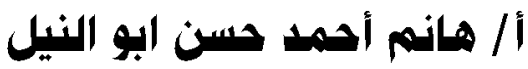

مـلدرس مسـاعـل بالقسيه

\section{مستخلص البدث باللغة العربية}

هدف البحث الحالى إلى التعرف علي تتمية الموارد البشرية وأهدافها، وأهم الإتجاهات الحديثة بشأنها، وأخيراً التوصل إلى إجراءات مقترحة لتمية الموارد البشرية بالجامعات في ضوء الإتجاهات الحديثة، واستخدم المنهج الوصفي لدراسة المشكلة، وتوصل فى نتائجه إلى مجموعة من الإجراءات المقترحة لتحقيق أهدافه، ومنها الاهتمـام بالتدريب المستمر على رأس العمل، تشـيع الأعمـال البحثيـة والتطويريـة وتعزيز الثقـة في البحث العلمي الجـامعي ودعمـه معنويًا وماديًا، عقد اللقاءات والمؤتمرات والندوات العلمية وغيرها، حيث تمثل هذه الروافد آليات لنقل وتبادل وتطوير المعرفة داخل الجامعة وخارجها بالثكل الذي يسهم في تتمية مواردها البشرية، وتحقيق تميزاً في أدائهم البحثي والعملي. 


\section{Ahstract}

\section{Human resources development in the universities in the light of the recent trends}

The objectives of the current research are to identify the meaning of the human resource development, its objectives, its related recent trends, and finally reaching the proposed procedures to develop the human resources in the universities in the light of the recent trends. The current research adopted the descriptive method to study the problem, and reached-via its conclusions - to a group of proposed procedures to achieve its objectives including paying full attention to on-job continuous training, encouraging the developmental and research projects, enhancing confidence in the university scientific researches and supporting them morally and financially, holding symposia, conferences and meetings etc.. Thus, these branches represent important mechanisms to develop, transfer, and exchange of knowledge within and outside the university in a way that contributes in developing its human resources and achieving excellence in their practical and research performance. 


\section{مقدمهــة}

يعد العنصر البشري في أي مؤسسة علي مختلف مستوياتها الإدارية الركيزة الأساسية

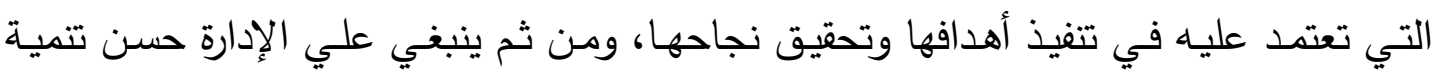

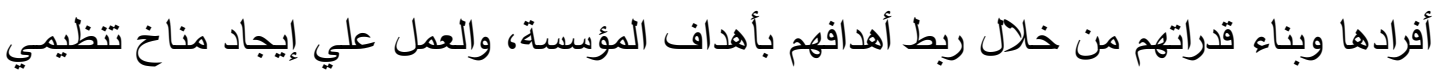

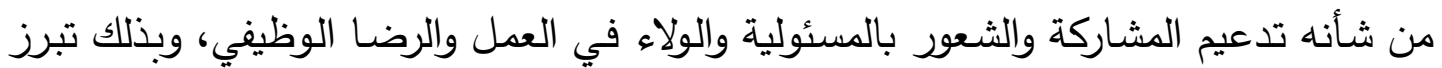
أهمية تتمية الموارد البشرية - من القيادات العليا إلي المستويات التتفيذية في كافة المجالات -

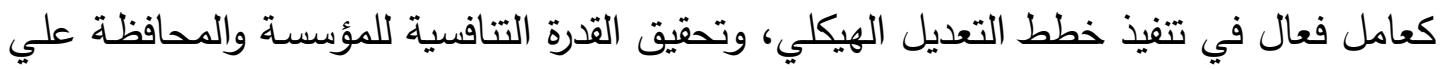
استمرارها وبقائها، وزيادة إنتاجيتها وتحسين أدائها في بيئة العمل المتغيرة.

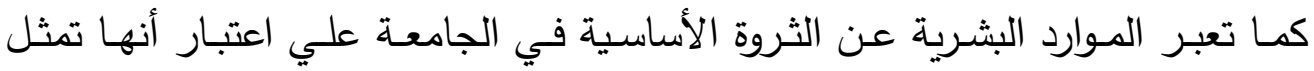

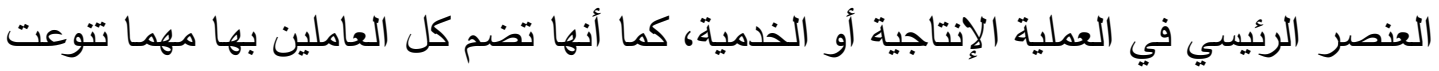

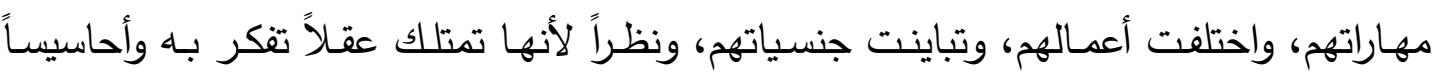

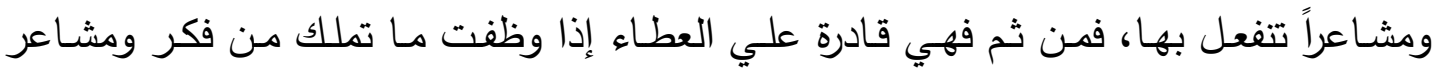

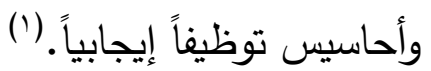
وبناءً علي ذلك جاء هذا البحث لدراسة تتمية الموارد البشرية بالجامعات في ضدوء

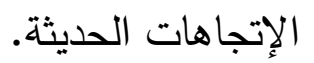

\section{مشكسة البدسبـ:}

تواجـه الجامعـات المصـرية مجموعـة متتوعـة مـن التحديات والمشكلات، التي تكبل حركتها وتقيد انطلاقها وتقلل من جودة الأداء فيها، ومن هذه المشكلات التوسع الكمي علي

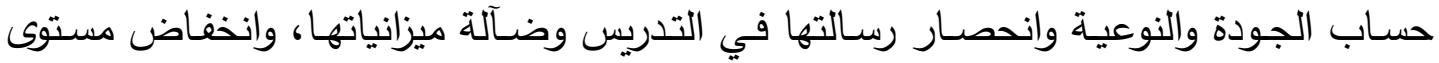

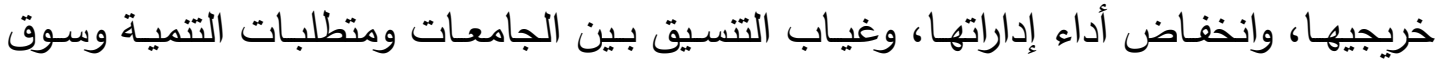

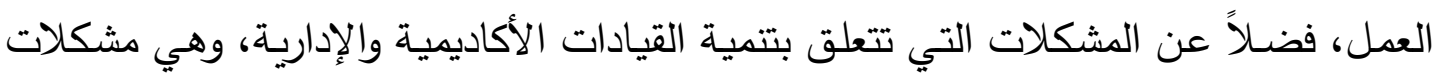

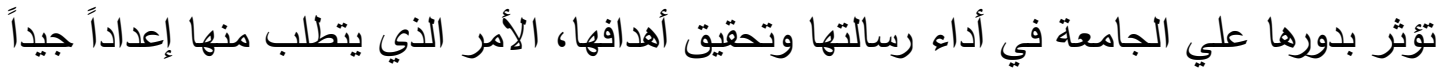
لمواردها البشرية، لكي تتمكن من تتفيذ رؤيتها وخطتها الإستراتيجية بكفاءة وفعالية، وتحقيق ميزة

تنافسية في السوق المحلي والدولي.(r) وفي ضوء ما سبق تبلورت مشكلة البحث في السؤال الرئيس التالي:

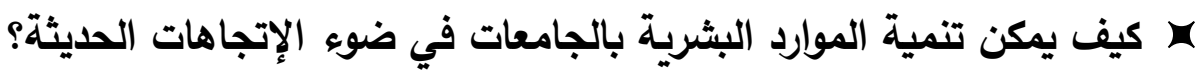


ويتفرع من هذا السؤل الرئيسي الأسئلة الفرعية التالية:

1- ماهية تتمية الموارد البشرية وأهدافها وفلسفتها ومبرراتها؟

r- ما أهم الإتجاهات الحديثة في تتمية الموارد البشرية؟

r- ما الإجراءات المقترحة لتتمية الموارد البشرية في ضوء الإتجاهات الحديثة؟

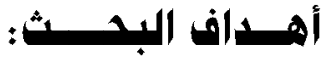

استهدف البحث الحالي التعرف علي تتمية الموارد البشرية من حيث مفهومها، أهدافها،

وفلسفتها، ومبرراتها، والتعرف أيضـاً علي أهم الإتجاهـات الحديثة في مجـال تتميـة الــوارد البشرية، وأخيراً التوصل إلى إجراءات مقترحـة لتنميـة الموارد البشرية بالجامعات في ضدوه

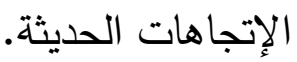

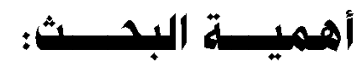

تكمن أهمية البحث في تتاوله قضية من القضـايا المهـة والتي تثغل فكر المهتمين بتطوير التعليم الجامعي وتحديثه وهي قضية استثمار الموارد البشرية بالجامعات وتتميتهم من

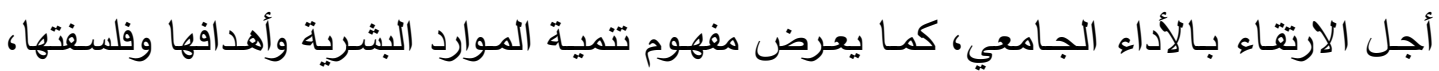
ومبرراتها، ويضع إجراءات مقترحة لذلك في ضوء الإتجاهات الحديثة.

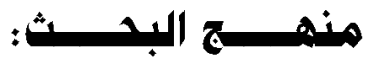

استخدم البحث الحسالي المنهج الوصفي لدراسـة المشكلة حيث يهتم بوصف الظـاهرة اعتماداً على جمع الحقائق والبيانات ومعالجتها وتحليلها تحليلاً كافيا لاستخلاص دلالتها وتقسيرها وتحليلها ولعلـه أنسـب المنـاهج للتعـرف على ماهيـة تتميـة المـوارد البشـرية وأهدافها وفلسفتها، ومبرراتها، والتوصل إلى إجراءات مقترحة لتتمية الموارد البشرية في ضوء الإتجاهات الحديثة. مصطادات البدـثـ:

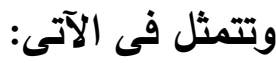

\section{Human Resources Development تنميـة المـوارد البشـريـة}

يقصد بها تلك العملية المتكاملة والمخططة موضوعياً والهادفة إلى إيجاد قوة عمل

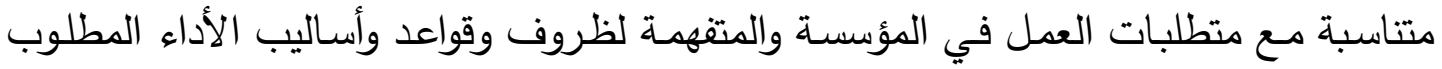


وإمكانياته، والقادرة على تطبيق تلك القواعد والأساليب والراغبة في أداء الأعمال باستخدام ما لايها من قدرات ومهارات. (r)

وتعرف أيضاً بأنها "التتمية الكلية للعنصر البشري على مستوى المجتمع، وتثمل جميع

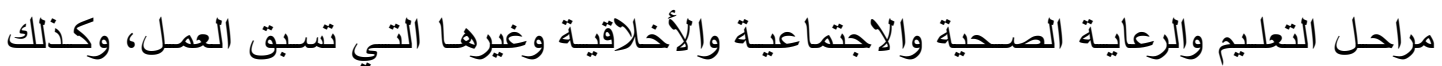

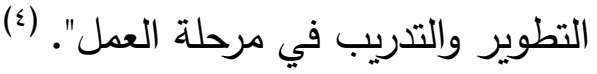
كمـا يقصد بها "أنثطة إدارة الموارد البشرية المصممة لتتميـة المهارات والاتجاهـات

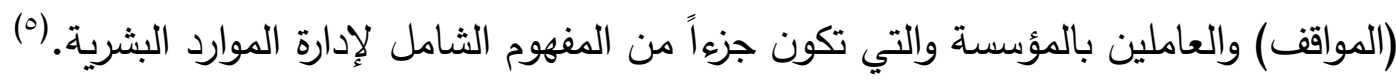

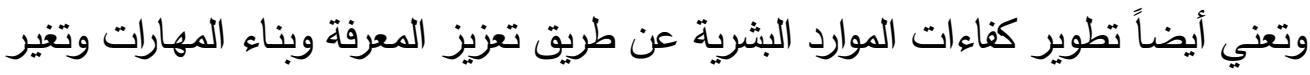

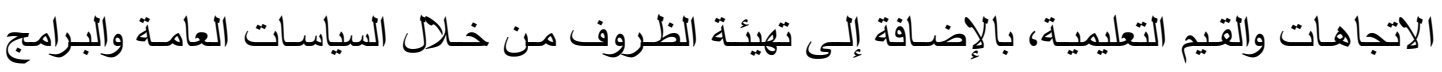

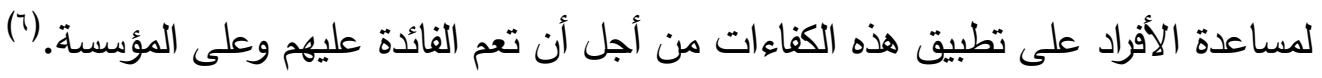

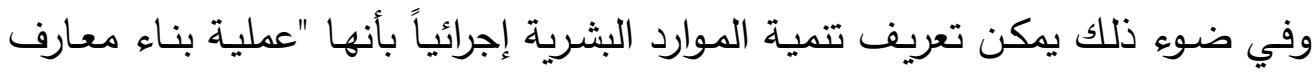
ومهارات وكفـاءات كافـة العـاملين بالمؤسسـة الجامعيـة - مـن القيادات العليا إلى المستويات التنفيذية - من خلال برامج التدريب والتعليم لتحقيق القدرة التنافسية للمؤسسة والمحافظة على الجى استمرارها وبقائها وتحسين أدائها في بيئة العمل المتغيرة".

بعد الاطلاع على أدبيات الفكر التربوي اتضح أن هناك مجموعة من الدراسات العلمية

$$
\text { ذات الصلة بموضوع البحث ومنها: }
$$

"أثثر إستراتيجية تنمية الموارد البثرية على أداء الأفراد في الجامعات: دراسـة حالة:

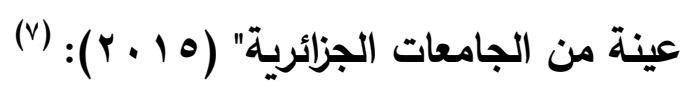

استهدفت الدراسـة تحديد أثر إستراتيجية تتميـة الموارد البشرية على أداء الأفراد في

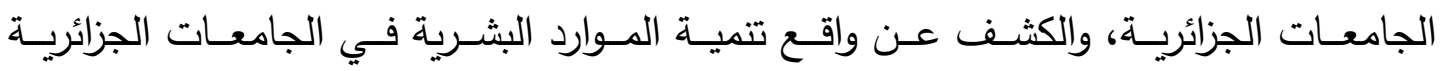
والإستراتيجيات المعتمدة فيها، واعتمدت على المنهج الوصفي التحليلي في وصف الظـاهرة

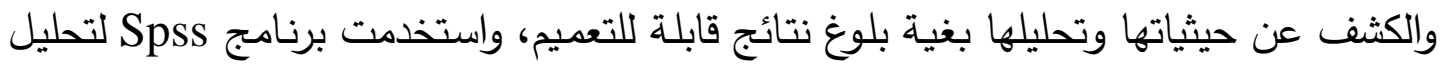

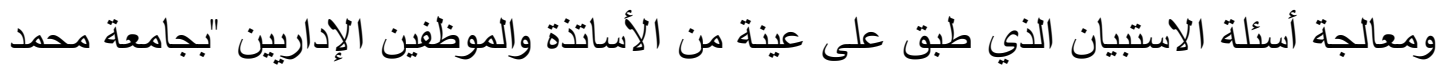

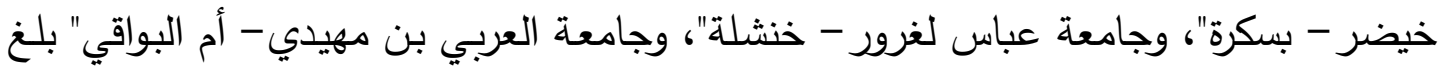




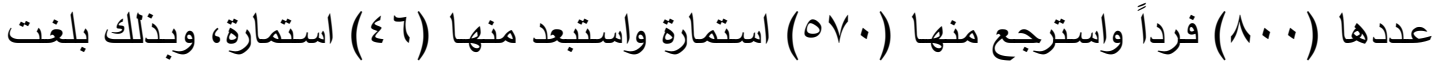

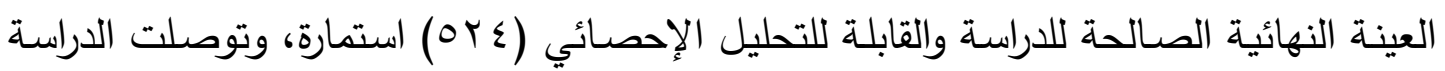

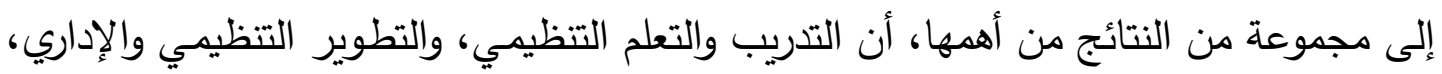

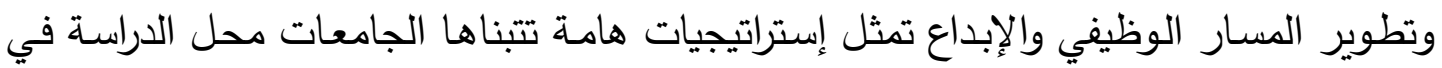

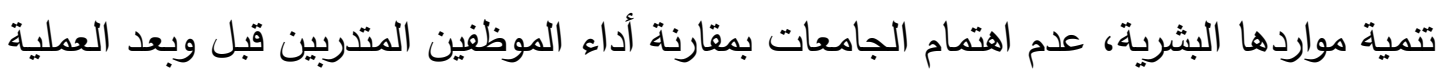
التدريبية وتقيييمه لتحديد مدى فعالية البرامج التدريبية، غياب التغذية الراجعة التي من شأنها الزيادة في صعوبة تحديد الإحتياجات التدريبية الفعلية، ومن ثم وضع برامج تدريبية لاتتبع من فئن

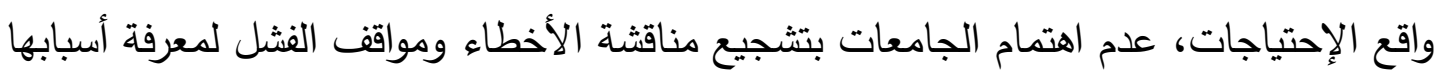

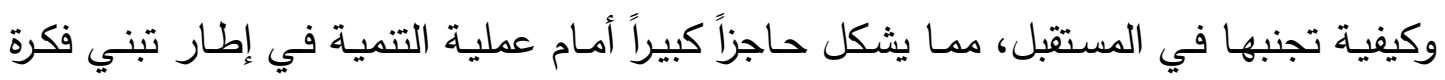
التعليم المستمر وتحول الجامعة إلى مؤسسة متعلمة، عدم إهتمام الجامعة بعامل حفز (مادي ومعنوي) لمكافأة الأفراد وفرق العمل الذين يخلقون طرق وأساليب ووسائل عمل جديدة.

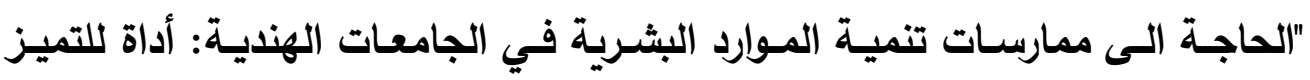

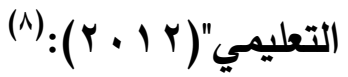
استهافت هذه الدراسة فحص المناخ لتتمية الموارد البشرية في الجامعات الهندية، قياس مستوى رضا أعضاء هيئة التدريس والاداريين بالجامعات تجاه الممارسات الحالية لتنمية الموارد

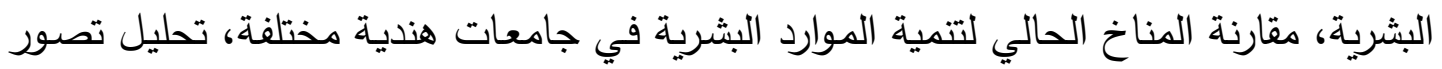
موظفي الجامعة تجاه الابعاد المختلفة لمناخ تتمية الموارد البشرية في الجامعات الهندية، اقتراح

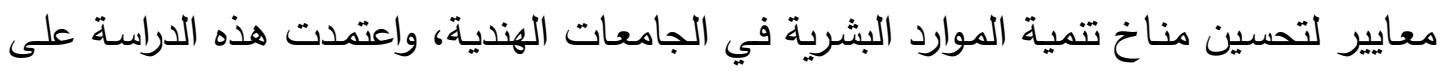

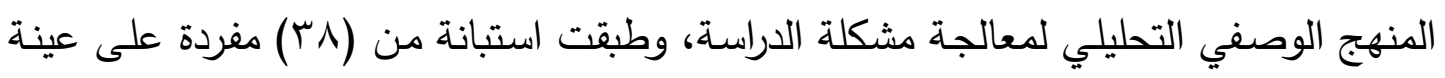

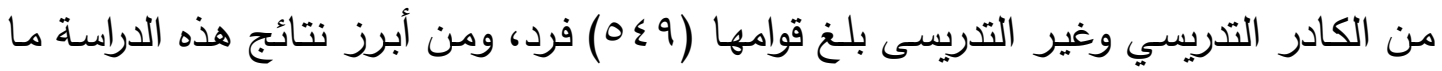

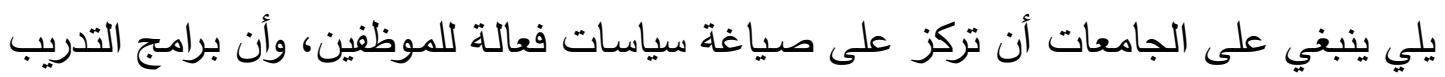

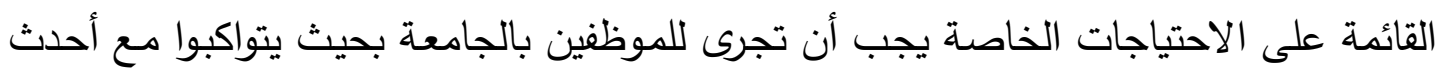

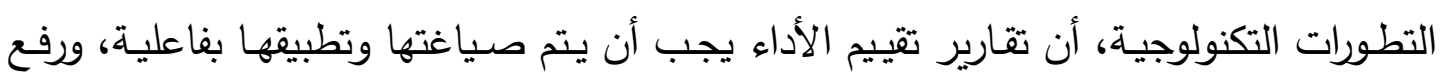

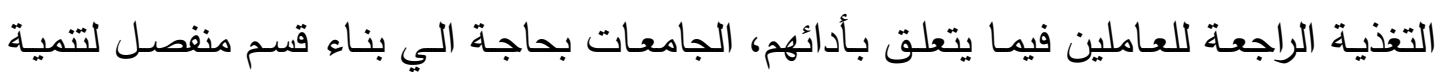
الموارد البشرية من اجل دعم تتمية العاملين. 


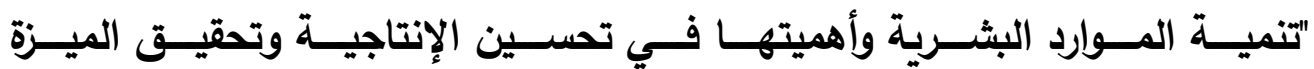

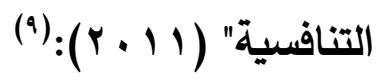

استهدفت هذه الدراسـة التعرف علي أهمية التدريب ودوره في تتميـة الموارد البشرية،

والوقوف علي أثر تنمية الموارد البشرية في تحسين الإنتاجية ودعم الميزة التتافسية للمؤسسة،

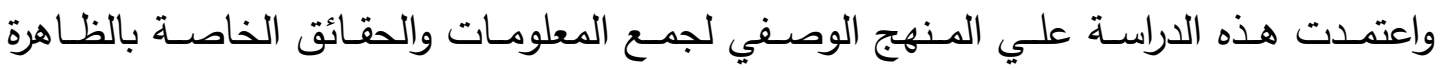

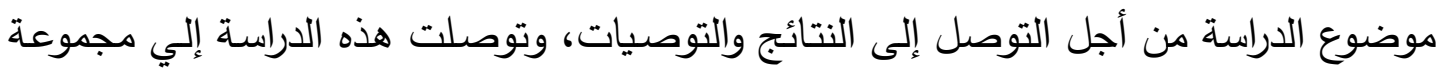
من النتائج أهمها: أن التدريب يعد أحد السبل المهـة لتكوين جهاز إداري كفؤ يتحمل أعباء

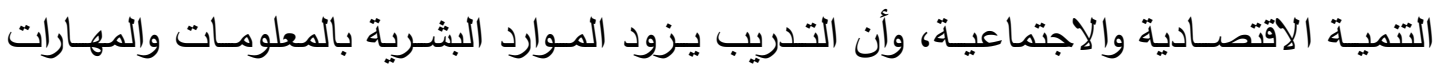
والأسـاليب المتجددة عن طبيعـة الأعمال الموكلـة إليهم وتحسين وتطوير مهاراتهم وقدراتهم ومحاولة تغيير سلوكهم واتجاههم بشكل إيجابي، وبالتالي رفع مستوي الأداء والكفاءة والإنتاجية.

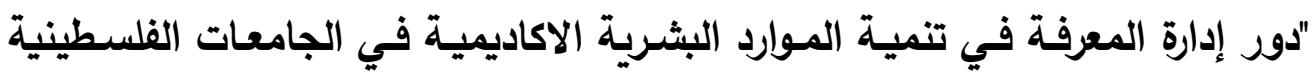

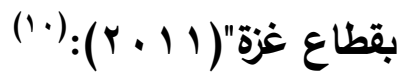
استهدفت هذه الدراسة التعرف على مفهوم إدارة المعرفة في مجال تتمية الموارد البشرية الاكاديمية في ظل الفكر الإداري المعاصر في الجامعات الفلسطينية بقطاع غزة، فضلا عن تحديد درجة ممارسة العاملين الأكاديميين لدور إدارة المعرفة وتتمية الموارد البشرية الاكاديمية

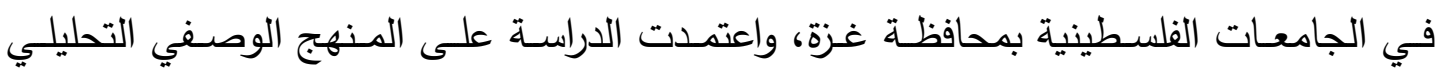

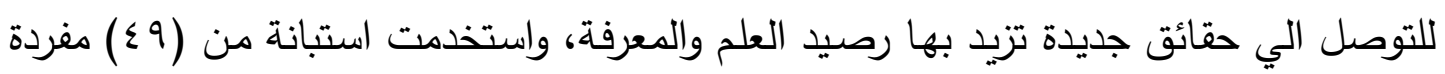
طبقت على عينة من جميع الاكاديميين العاملين في الجامعات الفلسطينية بقطاع غزة (الأزهر -

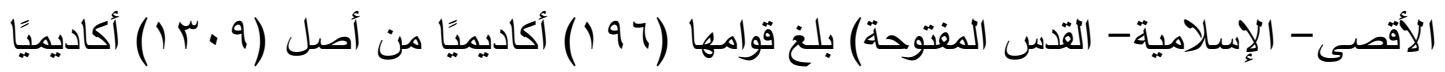

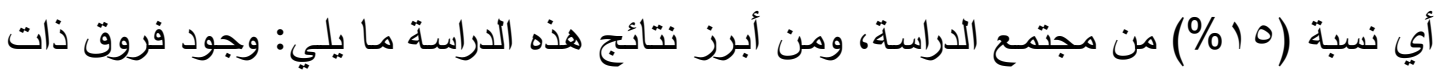
دلالة إحصائية لدرجة ممارسة العاملين الأكاديميين لدور إدارة المعرفة في تتمية الموارد البشرية لهردية

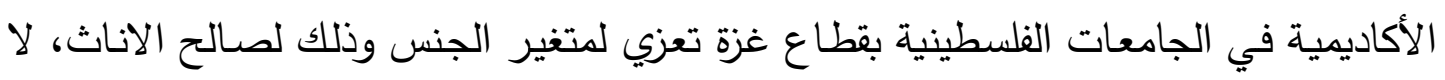

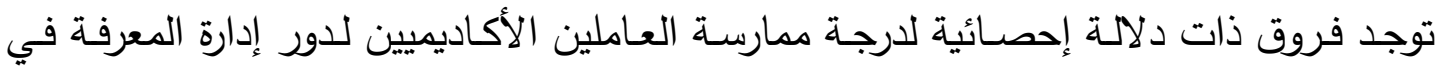

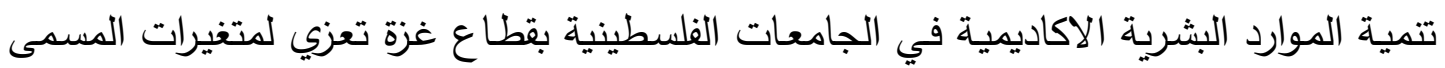

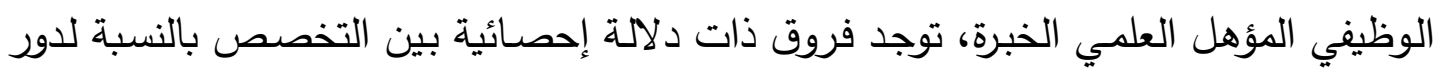


إدارة المعرفة في تنمية الموارد البشرية الأكاديمية في الجامعات الفلسطينية بقطاع غزة، وذلك

$$
\text { لصالح كلية الآداب والتجارة. }
$$

"تنميـة المــوارد البثـرية فــي ضـواء تطبيـق مبـادئ إدارة الجـودة الثــاملة فـي

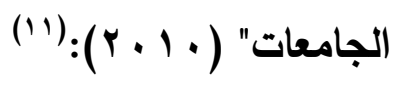

استهرفت هذه الدراسـة التعـرف علـي خطـوات بنـاء نظـام إدارة الجودة الثــاملة في

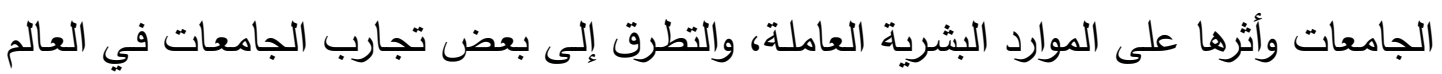

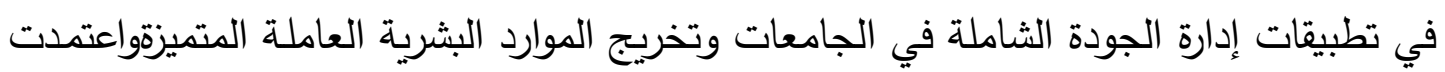

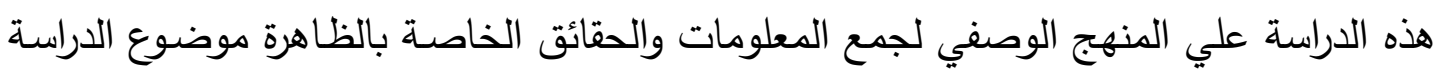

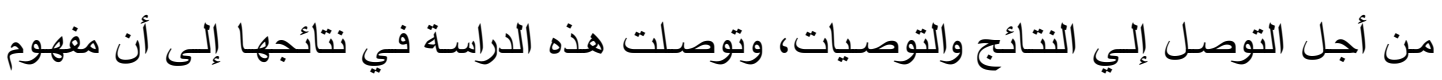

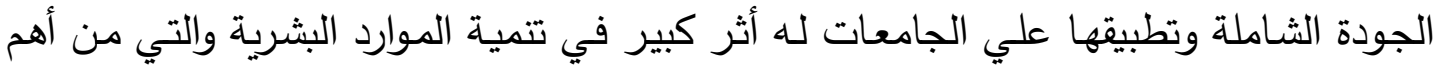

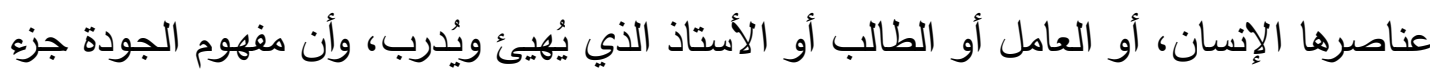

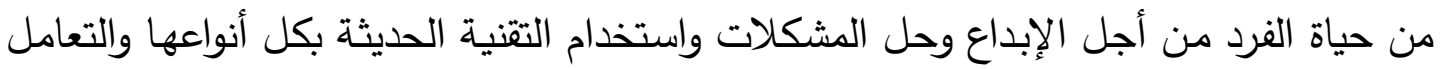

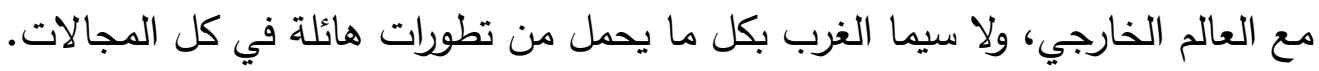

\section{أولاً : مفهوم تنمية الموارد البشرية وأهدافها وفلسفتها ومبرراتها :}

\section{1- مفهوم تنـميـة المـوارد البشريـة:}

تعـرف بأنها أحـد أنثطة إدارة المـوارد البشـرية المصدمة لتنميـة المهارات والمعـارف

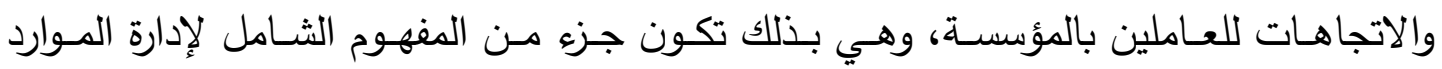

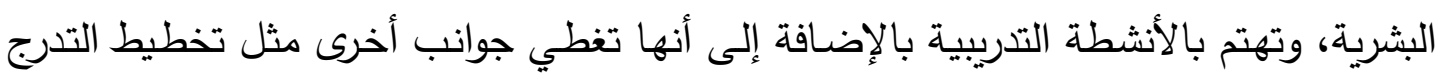

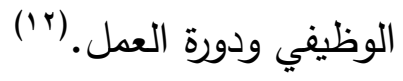
وتعرف بأنها مجموعة من الأنشطة المنظمة والمخططة تقوم بتصميمها المؤسسة لتزويد أعضائها بفرص تعلم المهارات اللازمة لمواكبة المتطلبات الحالية والمستقبلية للوظيفة، وما يركز بلهئ عليه هذا المفهوم بشكل أوضح هو سعي تتمية الموارد البشرية صوب تطوير الخبرة، والمعرفة،

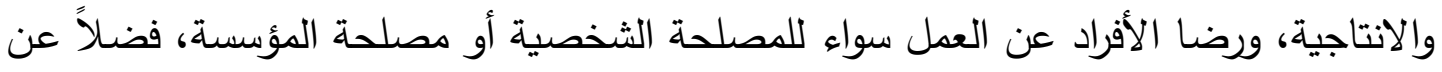

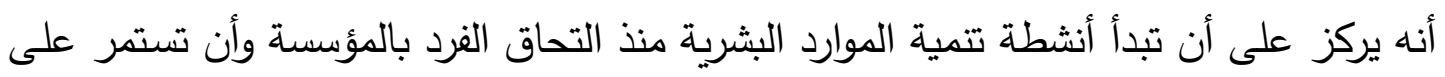

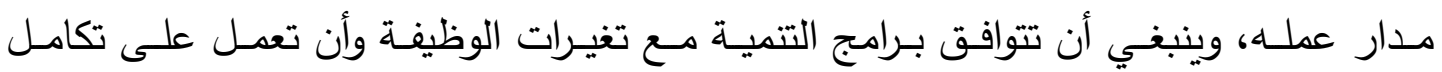
الاستراتيجيات والخطط بعيدة المدى للمؤسسة لضمان الاستخدام الفعال والأكثر كفاءة للموارد، تلعهل 
وأكد على أن الأنشطة مثل التدريب، والتطوير المهني، والتطوير التظظيمي، والتتميـة الإداريـة

وبناء الفريق تعد اتجاهات لتنمية الموارد البشرية. (rاب)

ومن خلال العرض السابق يتضح أن هناك مفاهيم عديدة لتنمية الموارد البشرية تركز في مجملها على مجموعة من الاغراض، منها تتمية المهارات والمعارف والاتجاهات لأفراد المؤسسة، تحسين الانتاجية وتحقيق الرضـا الوظيفي، تقييم العاملين بغرض إدراك قدرتهم للوظائف الحالية والمستقبلية، تحديد متطلبات تحسين الأداء نظراً للتغيرات التي تحدث في بيئة العمل.

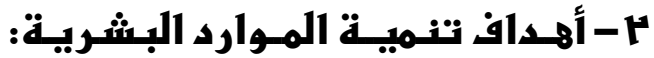

تُحقق عملية تنمية الموارد البشرية التي تقوم بها المؤسسة بشكل نظامي مجموعة من

الأهداف تتمثل فيما يلي:(؛)

تقويــة القــدرات المطلوبـــة لأداء مهــام مختلفـــة مرتبطــة بــأدوار الفــرد الحاليـــة والمستقبلية في المؤسسة.

تطوير وتحسين قدرات الأفراد واكتشـاف واستخدام طاقاتهم الكامنـة لأغراض شخصية تخصصهم وتخص تطوير المؤسسة. تطوير تتظيم الثقافة المؤسسية التي يكون فيها العلاقات بين الرئيس والمرؤوسين والعمل الجمـاعي والتعـاون بين الوحدات الفرعيـة قوى ويسـاهم في احتراف الأفراد، وزيـادة الدافعية وحفز العاملين.

\section{فضلاً عن تحقيقها مجموعة الأهداف التالية:(10)} تحسين وتطوير الأداء المهني لكافة العاملين بالجامعة. إحـداث التعـديلات والتغيـرات فـي أداء العـاملين بالجامعــة، بمــا يتفـق ومتغيـرات العصر الحديث. تحقيق مزيد من الترقي لدرجات علمية أعلى وأفضل. اكتسـاب المزيــــــن المهارات والخبـرات والمعـارف والمعلومـات التي تسهم في رفع المستوى الفكري والثقافي. التزويد بالطرق والأساليب العلمية الحديثة التى تسهم في رفع مستوى الأداء. زيـادة الخبرات لدى العاملين بما يمكنهم من اتخاذ القرارات في كافة الأعمال المناطـة بهم في مختلف المواقف داخل الجامعة. 
ومن الأهداف التي تدعمها تنمية الموارد البشرية بالجامعات ما يلي:

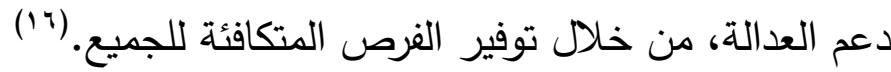
"دعم الديمقراطية وما تفجره من طاقات الإبداع والتحرر والمشاركة. ه دعم الانتاجية، عن طريق ترشيد استهلاك المصادر المحدودة.

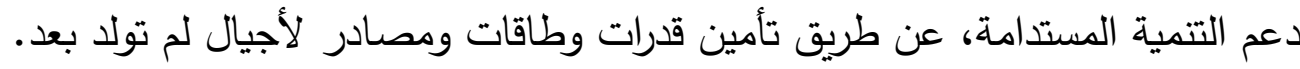

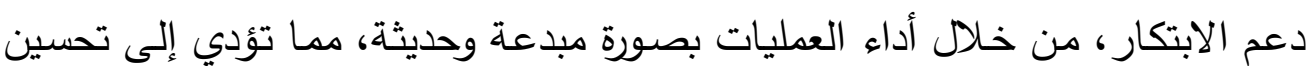

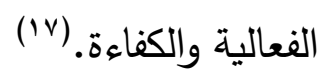
زيادة الكفاءة عن طريق أداء العمليات بسرعة وبأقل تكلفة. ه تحقيق الفعالية المؤسسية، وذلك عن طريق أداء العمليات الأكثر مناسبة أو ملائكـة وأخذ أفضل القرارات الممكنة. وبذلك يتضح من هذا العرض تعدد أهداف التتمية وشمولها، حيث تركز على تطوير

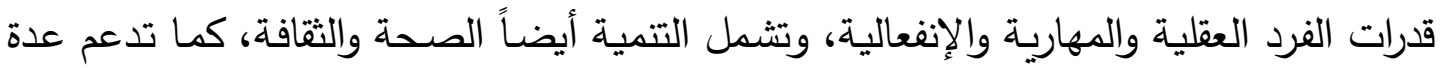
مبادئ كالعدالة، والديمقراطية، والإنتاجية والتتمية المستدامة، وتحقيق الفعالية المؤسسية.

\section{"م- فلسفة تنمية الموارد البشرية بالجامعات:}

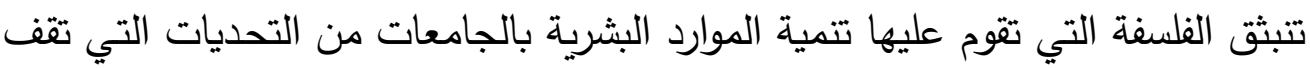

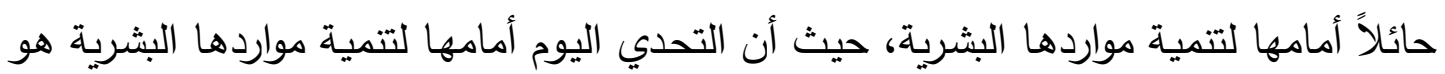

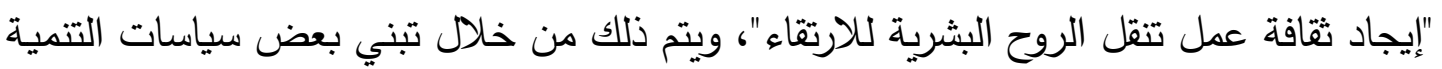

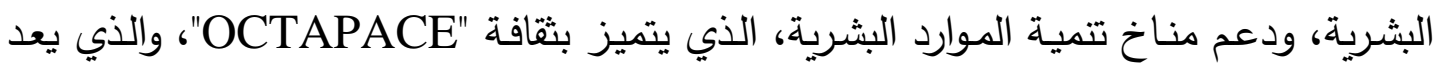
جزء متكاملاً من المناخ المؤسسي، وتعرف هذه الثقافة بمدى قدرة الأفراد على إدراك البيئة

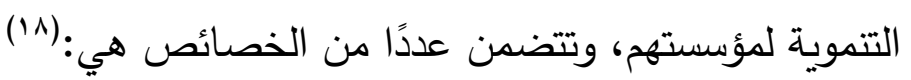
مقدار الأهمية المعطاة للموارد البشرية. مدى انفتاح عملية الاتصال بين أفراد المؤسسة.

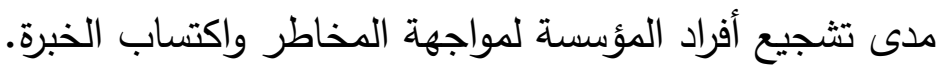

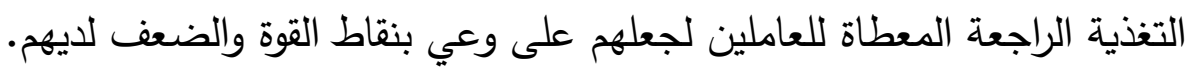
توفير مناخ عام من الثقة في المؤسسة. الثقة في قدرات الأفراد والعاملين. 


$$
\begin{aligned}
& \text { - مدى رغبة العاملين في التعاون ومساعدة بعضهم البعض. } \\
& \text { • إثاعة روح الفريق بين أفراد المؤسسة. } \\
& \text { • الرغبة في تثبيط الأفكار المسبقة والوساطة. } \\
& \text { " السياسات والتدربيات الداعمة الأفراد العمل. }
\end{aligned}
$$

\begin{tabular}{|c|c|c|c|}
\hline المؤش & القيهـــــة & & \\
\hline التــــــــرف على مشاعــــــــــــــــــــــ. & Openness & الانقتـاح & $\cdot$ \\
\hline مواجهة الشكلات وإيجاد حلول لها. & Confrontation & المسواجهــة & $\cdot$ \\
\hline 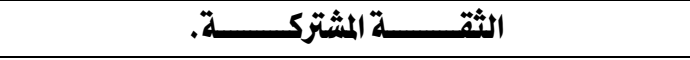 & Trust & الثقــــــة & $\cdot$ \\
\hline 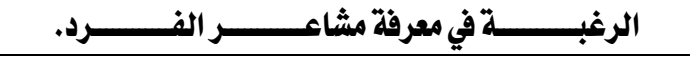 & Authenticity & الـوثــــوق & $\cdot$ \\
\hline رغبة المؤسسة في السبق في التأثير على الموقف، وليس مجرد & Proaction & التـــثير & $\cdot$ \\
\hline 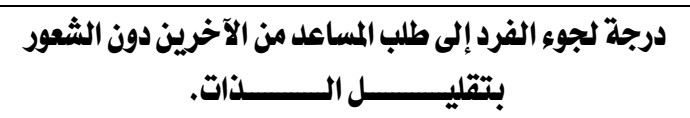 & Autonomy & 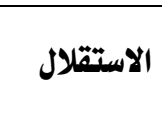 & $\cdot$ \\
\hline 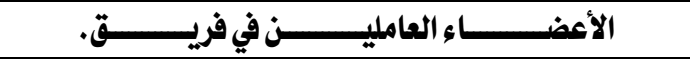 & Cooperation & التعــاون & $\cdot$ \\
\hline القيام بالعمل على أساس التجربة بشكل أساسي. & Experimentation & اكتساب الخبر & $\cdot$ \\
\hline
\end{tabular}

وبذلك يتجلى جوهر مناخ تتمية الموارد البشرية في الأهمية التي يعطيها لتطوير ثقافة

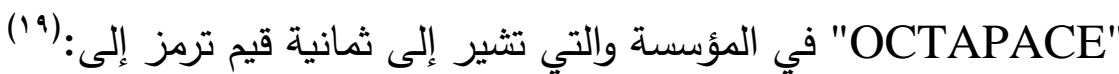

ويتضـح ممـا سـق أن ثقافـة "OCTAPACE" تعـد مطلبًا أساسيًا للمؤسسـة الفعالـة، ومناخًا أكثر دعمًا لنجـاح بـرامج تنميـة المـوارد البشـرية، حيث يجلب الانفتـاح أفكـاراً وطـرق ومهارات للمؤسسة ويحقق الرضـا، ويقدم التعاون والقوة للمؤسسة لكي تعمل وتواجه المشكلات وتعمل على حلها، والاستقلالية وخوض التجربة تمنح الأفراد فرصة للابتكار، وهكذا. كمـا تسـتـد فلسـفة تنميـة المـوارد البثـرية على مجموعـة مـن المبـادئ التـي ينبغسي

$$
\text { مراعاتها، ومنها(·) (r) }
$$

• ضرورة استثمار الموارد البشرية من أجل تحقيق أهداف المؤسسة بنجاح، وتحقيق الاستفادة القصوى لكل المعنيين بالمؤسسة.

" دمج خطط وبرامج تتمية الموارد البشرية من أجل تحقيق استراتيجيات الأعمال والموارد البشرية. • ضـرورة ارتبـاط بـرامج تنميـة المـوارد البشـرية دائدًا بـالأداء، وضــرورة تصــيمها لتحقيـق تحسينات محددة في الأداء المشترك والفردي والجماعي والوظيفي، ولتحقيق مساهمة كبيرة في الحد الأدنى للنتائج. 
• ضـرورة تثـيع أفراد المؤسسـة وإعطائهم الفرصـة للتعلم وتطوير مهاراتهم ومعـارفهم إلى

$$
\text { أقصى درجة. }
$$

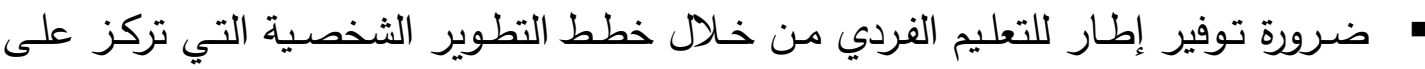
تدريب التحكم في الذات، وتكون مدعومه من قبل التدريب الرسمي والتوجيه.

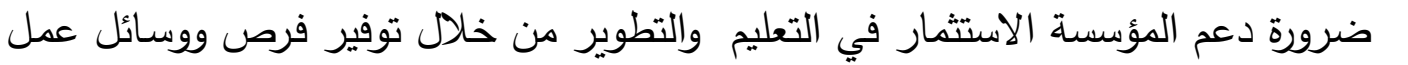

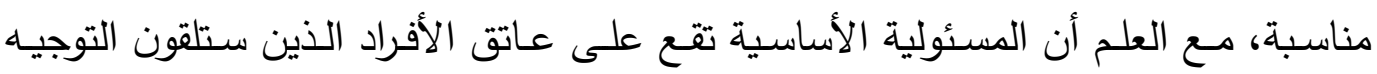
والدعم من مديريهم أو قسم الموارد البشرية إذا لزم الأمر .

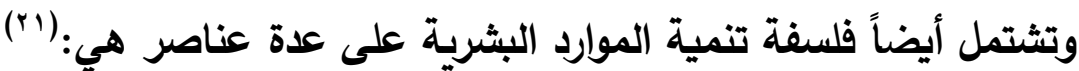

Education

هو عمليـة تطوير المعرفـة والقيم والإدراك المطلوبـة لجميع جوانب الحيـاة بـدلاً مـن المعارف والمهارات المتعلقة بمجالات معينة من النشاط.

\section{Learning التعل} ويعرف بأنه تغير دائم نسبيًا في السلوك الذي يحدث نتيجة للممارسة أو التجربة، وهو أكبر عملية تحدث في التكيف البشري.

\section{Training}

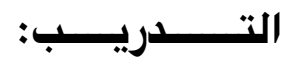

هو تعديل ممنهج ومنظم للسلوك من خلال تعلم المواقف والبرامج والتعليمات التي تمكن الأفراد من تحقيق مستويات المعرفة والمهارة والكفاءة اللازمة للقيام بعملهم على نحو فعال.

\section{Development التنمية أو التطوير:}

هي نمو وإدراك الفرد لقدراته وإمكانياته من خلال توفير التعلم والخبرات التعليمية. ومن خلال العرض السابق نوضح الفرق بين عناصر التتمية، حيث يعد "التعليم" مفهوم

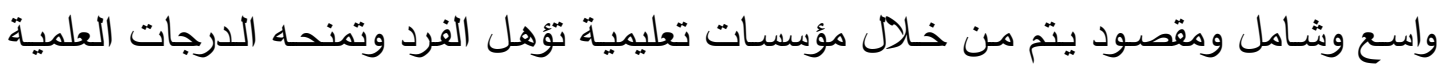

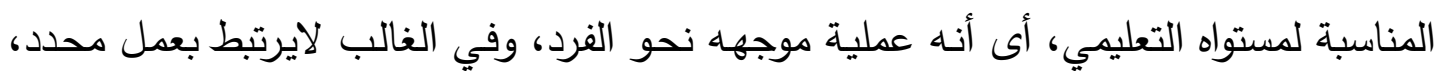
بينما "التعلم" عملية تلقائية تحدث نتيجة تفاعل الفرد بإمكاناته وقدراته ومستواه التعليمي مع البيئة المحيطة لتطوير ذاته، في حين أن التدريب موجه لتعديل أفكار واكتساب سلوكيات جديدة في سياق وظيفة الفرد الحالية، أي أنه موجه لوظيفة الفرد وليس الفرد ذاتهانه، بينما التتمية أو التطوير ترتبط بالإعداد للعمل المستقبلي وتتم بثكل تلقائي أو مخطط، وتوجه للفرد والمؤسسة. 


\section{ع- مبررات تنمية الموارد البشرية بالجامعات:}

تعزى تنمية الموارد البشرية بالجامعات إلى عدة مبررات منها:

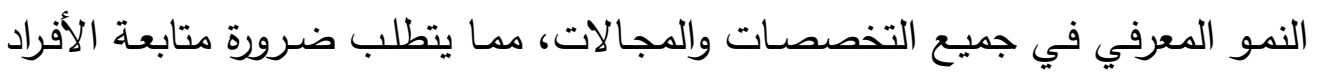

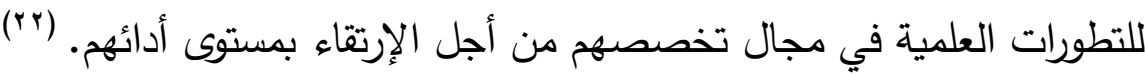

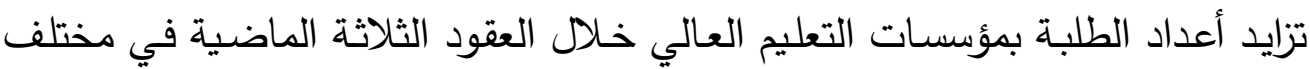

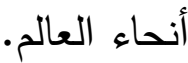
تحدي جـودة النوعيـة في التعليم العـالي، والـني أصـبح يثكل تحدياً يواجـه المسئولين والقيادات التعليمية. حاجة الجامعات لتأهيل القوى البشرية، وإعدادها للعمل في القطاعات المختلفة، وعلى القى

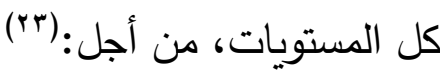
• التزويد بالمعارف والمهارات والقيم اللازمة للعمل المستهدف.

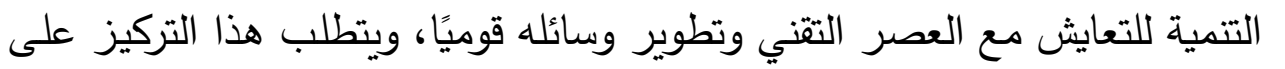

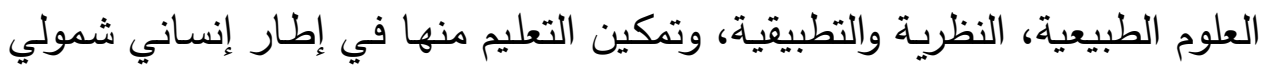
يدرك قيمة العلوم والمعارف الأخرى. حاجة الجامعة إلى ربط العملية التعليمية داخلها بالتدريب في مواقع الإنتاج ومجالات

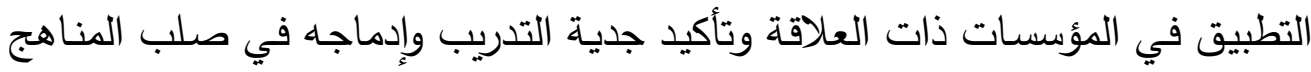

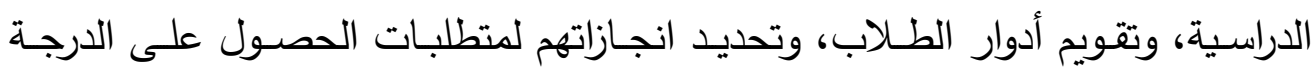
العلمية. (rs)

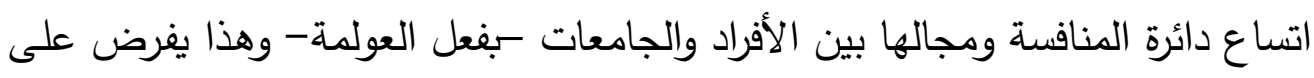

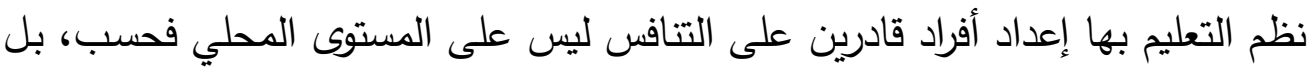

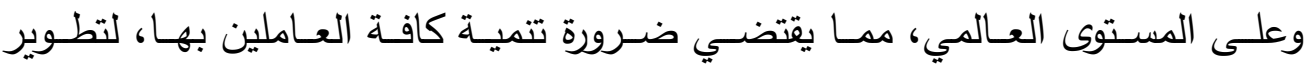
أدائهم. (ro) حاجة معظم الجامعات إلى دعم برامج "جودة الحياه الوظيفية"، والتي تستهدف تحسين مختلف الجوانب التي تؤثر على الحياه الوظيفية للعاملين وحياتهم الثخصية أيضاً،

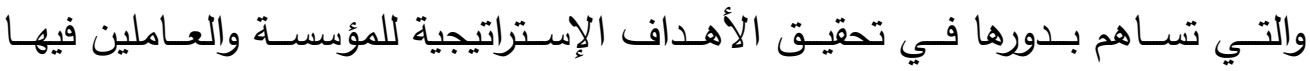

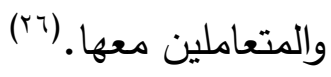


ومن خـلال هذا العرض يتضـح تنوع المبررات من اجل التتمية البشرية بالجامعات،

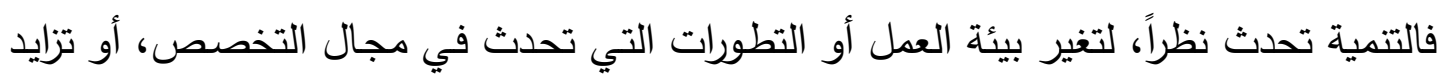
أعداد الطلبة وتحدي الجودة أو لتأهيل الأفراد حسب الاحتيل التطورت التياجـات المتغيرة أو لتحسين جودة

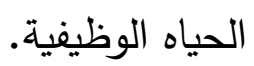

\section{ثانياً : الاتجاهات الحديثة في تنمية الموارد البشرية :}

لقد ركزت معظم الإتجاهات الحديثة على تتمية الموارد البشرية في أحد جوانبها تأكيداً

$$
\text { على أهميتها، ومن هذه الاتجاهات مايلي: }
$$

\section{1- إدارة الجـــــودة الشــاملــة:}

تعرف إدارة الجودة الثـاملة بأنها طريقة مختلفة لتنظيم جهود الأفراد، بهدف توحيد

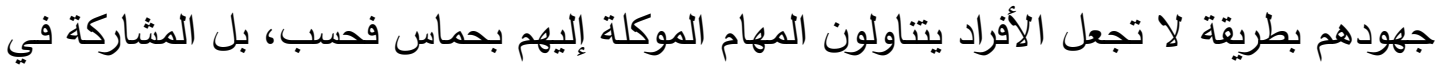

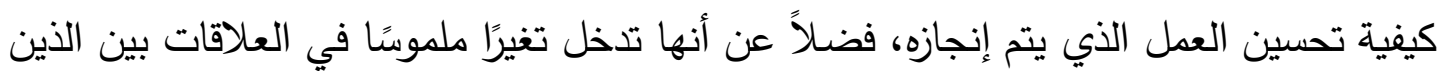

يديرون والذين يعملون بالفعل، كما أنها تركز على:(rV)

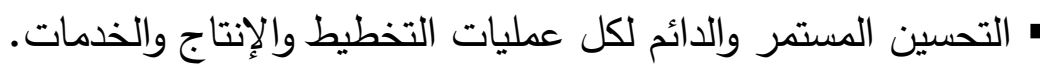
• الاهتمام بالتدريب المستمر على رأس العمل. • القضاء على الخوف لاى القيادة والعاملين. • كسر الحواجز في الاتصالات بين العاملين. • بدء برنامج قوي للتثقيف والتحسين الذاتي لكل فرد.

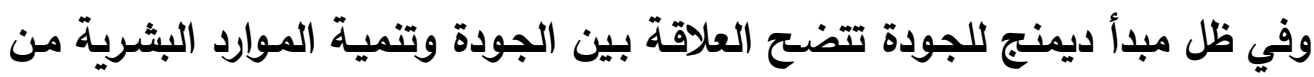

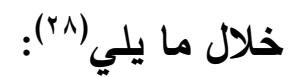
• التدريب على الوظيفة، ويتطلب ذلك: تقديم التدريب بواسطة أفراد مشهود لهم بالكفاءة. استمرار التدريب حتى يصل المنتج إلى مستوى مرضي. • وضع برنامج نشط للتدريب والتعليم، ويتطلب ذلك. • أن تركز الإدارة على أن تطوير الإنتاج لا يعني اختفاء أي وظائف.

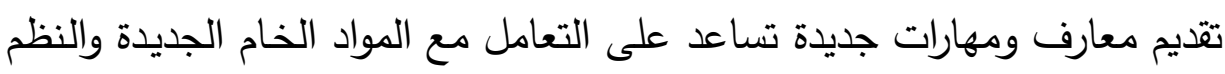

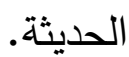


النظر إلى التعليم وإعادة التدريب على اساس أنه استثمار في البشر وضروري من أجل التخطيط طويل المدى. • تخفيض المعوقات والحدود بين الأقسام الوظيفية لبناء فرق العمل.

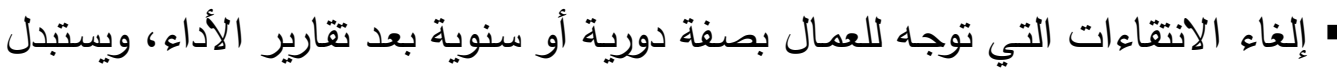
بها تقارير توضح القدرات والمهارات التي يتميز بها الأفراد. • التأكيد على الرقابة الذاتية والاستقلالية والإبداع بين العاملين. " دعم التعاون بدل من الإذعان والخضوع للأوامر والتعليمات.

وفي ضوء مفهوم الجودة الثاملة تركز الجامعات على تتمية مواردها، من خلال تبني مبدأ التحسين المستمر لخريجيها والعمليات والخدمات المقدمة، وذلك عن طريق (ra):

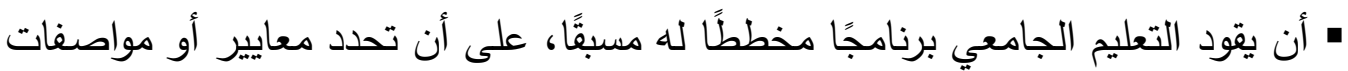
الإنجاز في ذلك البرنامج ليتم في ضوئها القياس والتتويم. • عقد الدورات التدريبية لمختلف العاملين داخل المؤسسة الجامعية. • استمرار عملية قياس جودة النظام الجامعي في مدخلاته وعملياته ومخرجاته. وفي

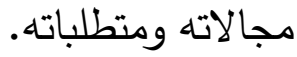

" التزام أعضاء هيئة التدريس ومعاونيهم بالتتمية المهنية الدستمرة، وأنثطة التعليم الجامعي. • تحديد المستفيدين من نظام التعليم الجامعي لقياس رضاهم. • ترك سبل الاتصال مفتوحة بين كل العاملين في المؤسسة الجامعية وخارجها للتمكن من تقديم المقترحات التي من شأنها تطوير التعليم الجامعي ودعم التتمية به. - الاشتراك في عضوية المؤسسات التزبوية والعلمية على المستوى الإقليمي والعالمي، مما يثجع المساهمة والتعاون في تطوير التعليم الجامعي. - المساهمة في الندوات والمؤتمرات العلمية على المستوى الإقليمي والعـالمي للاطلاع على مختلف المستجدات بثأن تتمية الموارد البشرية وتطوير التعليم الجامعي.

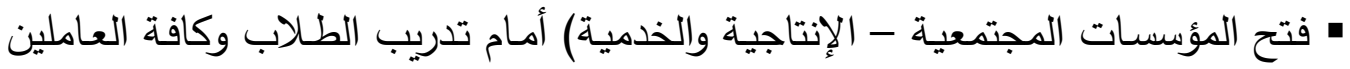
لاعم التنمية البشرية. • تثجيع الأعمال البحثية والتطويريـة وتعزيز الثقة في البحث العلمي الجامعي ودعمـه

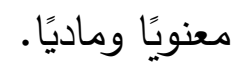


وبذلك يتضح أن نظام الجودة يؤكد على الإستثمار الأمثل للموارد البشرية على اختلاف

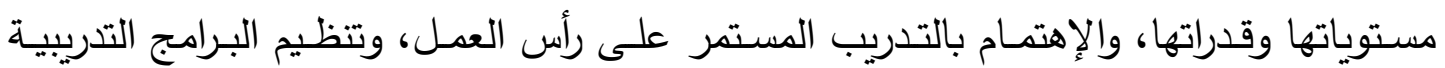

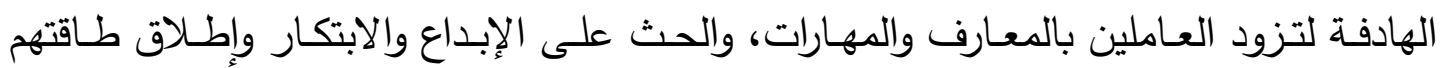
الكامنة من أجل تطوير الأداء.

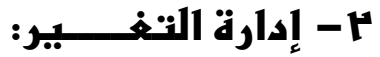

تعبر إدارة التغيير عن كيفية استخدام أفضل الطرق اقتصاديا وفعالية لإحداث التغيير لخدمة الأهداف المنشودة، والتغيير قد يكون (r·): من أعلى إلى اسفل، اي يأخذ اتجاه خط السلطة، حيث تستخدم الإدارة العليا سلطاتها

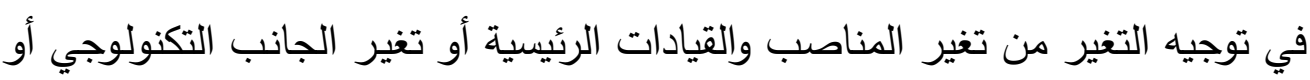
إعادة التنظيم، ويحقق هذا الأسلوب السرعة في إدخال التغيير وتنفيذه، وإن كان لـه

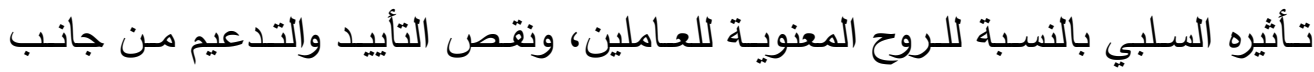
المستويات الإدارية الدنيا. من أسفل إلى أعلى، أي تأتي المبادرة لإحداث التغير من جانب المستويات الإداريـة

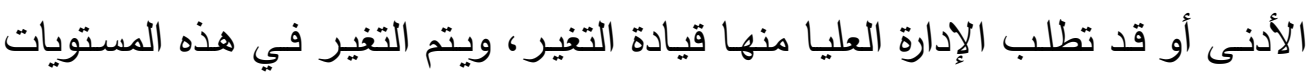

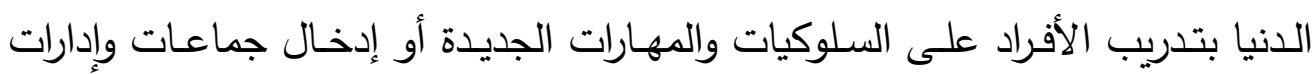
استثارية جديدة لاقتراح الطرق الجديدة في أداء الأعمال أو تطبيق التغير • ويدعم التغير تتمية الموارد البشرية من خلال ظهور بعض نماذج التغير التي تمتلك لكئك أدوات متتوعـة ومميزات تساعد القائمين على تتميـة الموارد البشرية في اختيار الاستراتيجية

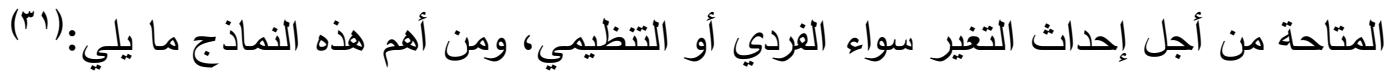
نمسـودج مــاكــنزي Mckinsy و وآخرون (نموذج 7S): يقوم هذا النموذج على عنصرين أساسين هما الفاعلية التنظيمية التي تتأتى من التفاعل

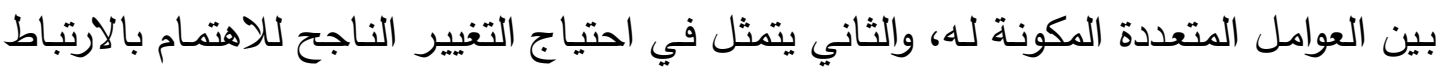

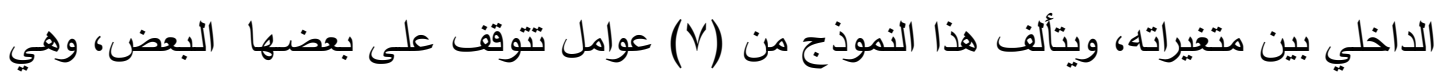
(البنية، الاستراتيجية، النظم، الاسلوب، فريق العمل، المهارات، القيم المشتركة)، وفيما يلي شرح موجز لكل عامل من هذه العوامل على حدة: 
وتثير إلى التصميم التتظيمي وتتضـمن عدة عناصـر منها، درجـة الهرميـة، ومدى المركزية واللامركزية، تحديد الأدوار والمسئوليات، تقييم فاعلية النظم البشرية، والمالية والتقنية،

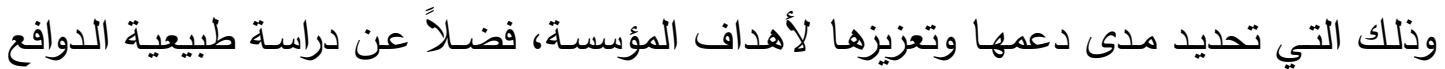
والمحفزات في الموارد البشرية، ووضع ميزانية للسياسات والاجراءات.

\section{Strategy r الاستراتيجية}

وتثير إلى الدرب الذي تختاره المؤسسة لتصل عبره إلى النجاح التتافسي، وتتضمن رؤية المؤسسة وتوجهها، بالإضافة إلى وسائل وسُبل توصيل واستخدام وتفعيل رؤية المؤسسة

\section{Systems r النظـــ}

وهي تلك الاجراءات المتتوعة في مجالات مثل "تكنولوجيا المعلومـات"، والتي عن

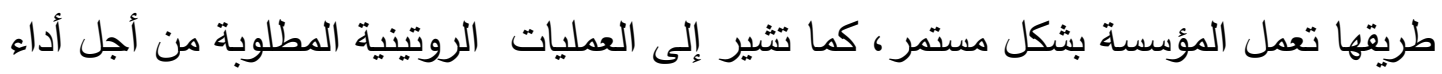
العمل، بما في ذلك أساليب تناقل المعلومات عبر المؤسسة.

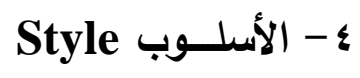

ويشير إلى اليُبل التي يتبعها الرؤساء لتحديد الأولويات، وكيفية تصرفهم من أجل

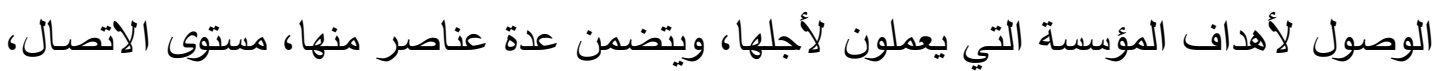
مدى وجود بيئة داعمة لفريق العمل.

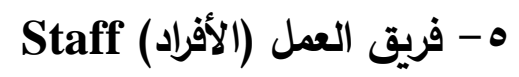
ويشير إلى عمليات تتمية الموارد البشرية، ومن النقاط التي يمكن دراستها في هذا البعد

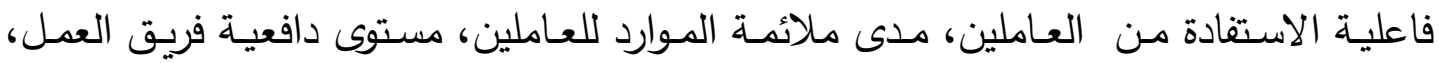
وغيرها من العوامل التي قد تزيد من الرضا الوظيفي.

Skills المهـــارات

وتوصف بأنها السمات المحورية "أو القدرات البارزة" في مجالات مثل خدمة العملاء، وضبط الجودة، والإبداع والتي تميز مؤسسة ما عن منافسيها، ومن المفاهيم التي تركز على دراستها مدى التوافق بين العمل ومهارات الأفراد، مدى توفر الفرصة لمشاركة التدريب. 
Shared Value القيم المشتركة - V

وتثير إلى "رؤيسة المؤسسة"، فهي الايمان الحقيقي في أصل قيام المؤسسة وتوقعات

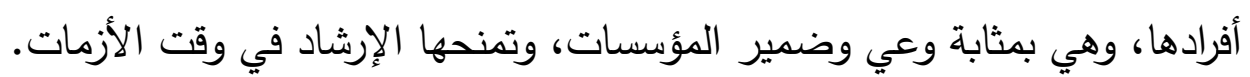

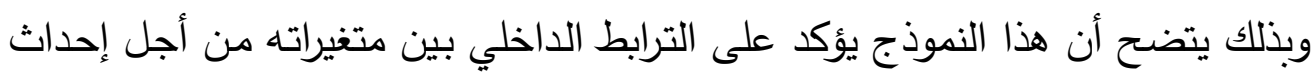

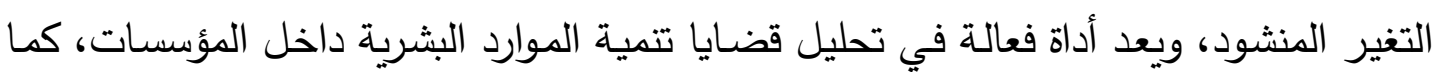
يعد أداة لتتييم الصراعات المختلفة عند تطبيق البرنامج التتموي، كما يسعى إلى تغير في البنية التئي

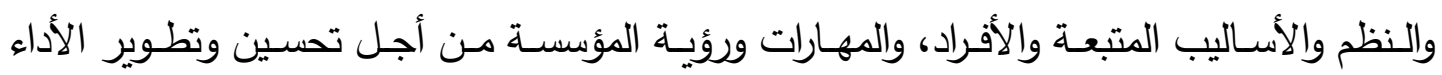
التتظيمي، وتحسين الفاعلية المؤسسية ككل، وهذا بدوره يوفر مناخ إيجابي من أجل التتمية البشرية.

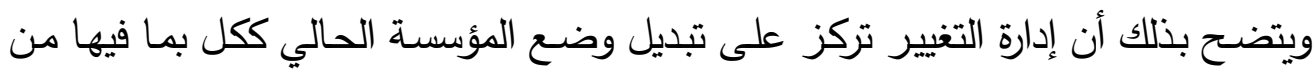

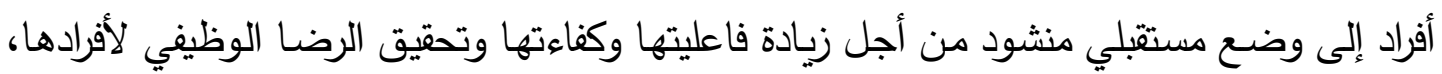
وذلك من خلال تبني نظام فعال للتمية المهنية والتتريب، ودعم التعليم الدستمر لكافة أفرادها.

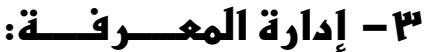

تلعب إدارة المعرفة دورًا حيويًا في بناء المؤسسة، حيث أنها تؤثر وبشكل كبير على

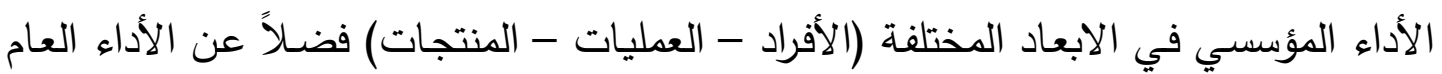

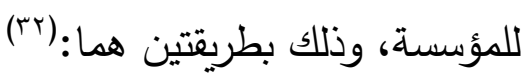

توليد المعرفة ذاتها التي تستطيع المساهمة في تحسين أداء المؤسسة في المستويات الأبعة. التأثير المباشر في التحسينات الضرورية للأبعاد الأربعة.

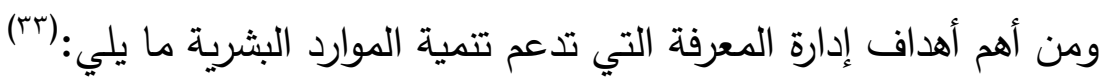
هذب رأس المال الفكري لوضع الحلول للمشكلات التي تواجه المؤسسة. خلق البيئة التنظيمية التي تثجع كل فرد في المؤسسة على المشاركة بالمعرفة. ه تحديد المعرفة الجوهرية وكيفية الحصول عليها وحمايتها وإعادة استخدامها. التأكد من فاعلية تقنيات المؤسسة، ومن تحويل المعرفة الضمنية إلى معرفة ظـاهرة وتعظيم العوائد من الملكية الفكرية. تحول المؤسسات من الاقتصاد التقليدي إلى الاقتصاد العلدي الجديد (الاقتصاد القائم على المعرفة). تطوير الأداء المؤسسي من خلال التخطيط وإدارة وتطوير أداء العاملين وإدارة المؤسسة. 


$$
\begin{aligned}
& \text { ه تبني فكرة الإبداع عن طريق تثجيع مبدأ تدفق الأفكار بحرية. } \\
& \text { تحسين صورة المؤسسة وتطوير علاقتها بمثيلاتها. }
\end{aligned}
$$

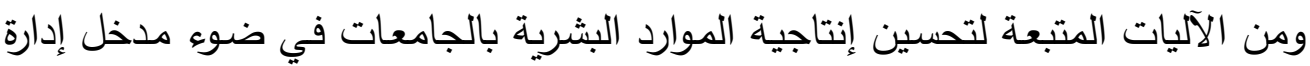

المعرفة ما يلي:(«ّ)

إنثـاء قاعدة معرفيـة بكل جامعـة تخدمها شبكة اتصـالات حديثة، أي توفير قواعد للبيانـات ومستودعات إلكترونيـة لتخزين المعرفـة، بحيث تكون متاحـة لجميع أفراد

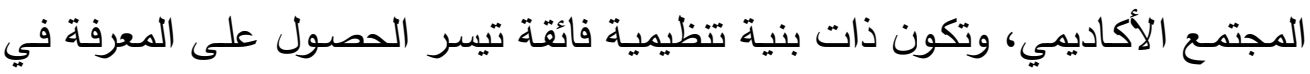

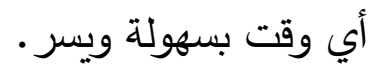

استحداث نظم اتصال فعالة بين الجامعات المختلفة بعضها وبعض وبينها وبين مراكز البحوث بما يضمن التكامل وعدم التكرار للموضوعات.

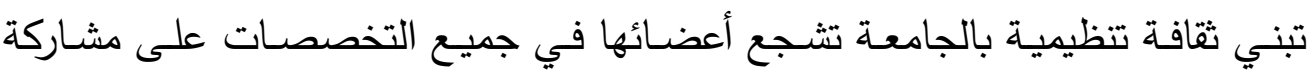
المعرفة وتبادلها بشكل فعال، وتكافئ من يملكها.

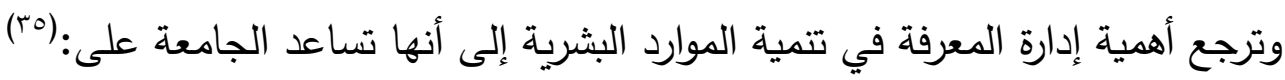
تحقيق الفعالية التظظيمية، ويتم ذلك من خلال: بناء وتتمية قدرة الجامعة على الاستخدام الأمثل لمواردها المختلفة. إطلاق الطاقات الفكرية والقدرات الذهنية لأفراد الجامعة على كافة المستويات، ومن الفناء ثم المساهمة في رفع كفاءة العمليات وتحسين إنتاجية المؤسسة. توفير المعرفة التي تتناسب مـع الموارد المتاحة داخل الجامعة واساليب استيعابها وتحريكها لخدمة الأهداف التي تسعى إليها.

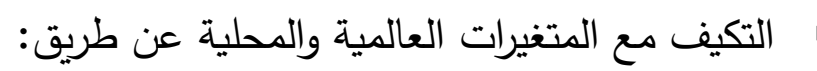
توفير المعرفة بتلك المتغيرات ومصادرها واسبابها ومنطلباتها بثكل أفضل. تكوين واستثمار حصيلة معرفة وثقافات المجتمع المختلفة. بناء وتتمية قدرة الجامعة على التعامل مع المتغيرات وزيادة إحساسها بإرهاصـات التغير في توقيت مبكر . تصناء تحقيق التكامل بين قدرات الموارد البشرية المبدعـة من ذوي المعرفة من جانب ومتطلبات تقنيات الاتصال والمعلومات من جانب آخر . 
القدرة على المنافسة والبقاء، وذلك من خلال:

تجديد الرصيد المعرفي والتخلص من المفاهيم والخبرات المتقادمة التي تعجز عن مواكبة معطيات الظروف الجديدة والمتغيرة باستمرار .

توفير حجر الأساس الذي تقوم عليه منظومة القدرات المحوريـة للجامعة وإمكانياتها

لبناء وتتمية وتفعيل قوتها التتافسية.

مساندة الإدارة في عملية التجدد الفكري من خلال استقبال المفاهيم والخبرات الجديدة

واستيعابها وتوظيفها في تتمية الموارد البشرية، ومن يقدر على إبداع معرفة جديدة.

تبني عدد من الإجراءات التنظيمية التي تسمح بنقل المعرفة الضمنية المخزنة في عقول

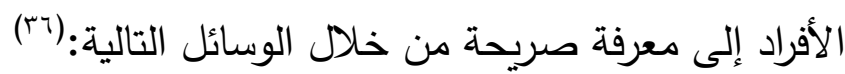

اللقاءات والمؤتمرات والندوات العلمية وغيرها، حيث تمثل هذه الروافد آليات لنقل

وتبادل وتطوير المعرفـة داخل الجامعـة وخارجها بالثكل الذي يسهر في تتميـة

$$
\text { مواردها البشرية، وتحقيق تميزاً في أدائهم البحثي والعملي. }
$$

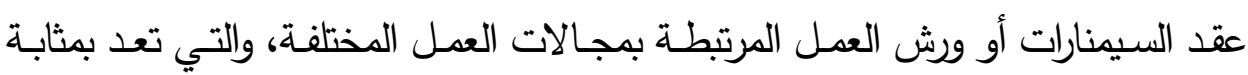
قنوات تتيح فرص نقل وتبادل المعرفة وتثارك الخبرات بين أعضاء المجتمع الأكاديمي. تعميم نظام المكتبة الإكترونية داخل كليات الجامعات المختلفة بحيث تكون مزودة

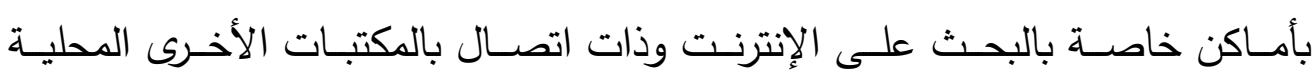
والعالمية، مما ييسر عملية الحصول على المعرفة وتبادلها وإبداعها. تطوير نظم النشر الإلكتروني لتيسير إجراءات النشر العلمي في المجالات والدوريات

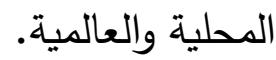

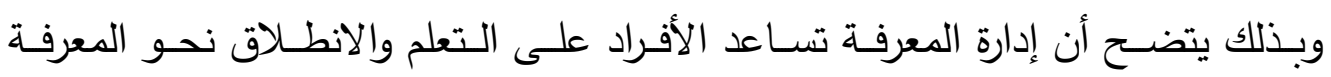
المتجددة كل في تخصصـه، كما تسهم في تطوير وتتمية مواردها البشرية من خلال تخطيط التدريب على فترات تستمر طوال حياة الفرد الوظيفية.

\section{ع- إدارة التنمــيزز:}

يعرف التميز بأنها مجموعة المعارف والمهارات والقدرات التي يمتلكها أصحاب الأداء

المتميز ، وتساعدهم على أداء مجموعة من المهام الوظيفي في ظل ظروف بيئة متغيرة. (rv) 
بينمـا تعرف إدارة التميز بأنها جهود تتظيميـة مخططـة تهدف إلى تحقيق المميزات

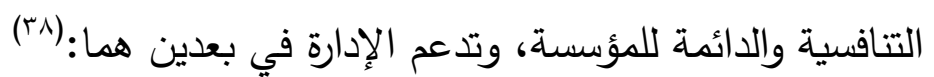
البعد الأول: أن غاية الإدارة الحقيقية هي السعي إلى تحقيق التميز، بمعنى إنجاز نتائج غير مسبوقة تتفوق بها على كل من ينافسها بل وتتثوق بها على نفسها بمنطق التعلم. • البعد الثاني: أن كل مـا يصدر عن الإدارة من أعمال وقرارات ومـا تعتمده من نظم وفعاليات، ينبغي أن يتسم بالتميز أي الجودة الفائقة الكاملة التي لا تترك مجالاً للخطأ أو الانحراف.

وهي في الأسـاس "إدارة متميزة للموارد البشرية، حيث أن الأداة الحقيقية والقوة الفاعلـة في تحقيق غايات وأهداف المؤسسات هم "الموارد البشرية" من العاملين ذوي المعرفة الذين يتم اختيارهم بعنايـة فائقة، وتوفر لهم الإدارة فرصـة التتميـة المستمرة والتدريب الهادف إلى زيـادة مهاراتهم وتستثمر قدراتهم الفكريـة والمعرفية في تطوير الأداء وتمكنهم دائمًا من السيطرة على لإدى مقدرات العمل وحرية الحركة والمشاركة في تحمل المسئوليات واتخاذ القرارات. (ra) كمـا ظهرت نمـاذج عديـدة لإدارة التميز تعمـل على تحديـ معـيير التميز ومقومـات نجاحه، وهذه النماذج لها خصائصها التي تنفرد بها ولكنها تشترك في محاولة تحسين الأداء وصـولا إلى التميز، ومـن هذه النمـاذج النموذج الياباني لديمنج، النموذج الأوروبي، النمـوذج الأمريكي بالدريج، ومن المعايير التي تركز عليها هذه النمـاذج "الأفراد" أو "الموارد البشرية" ويتناول هذا المعيار إدراك الجودة، ووعى الإدارة بمهمة مراقبة الجودة من خلال وضـع خطط لتعليم وتدريب الموارد البشرية بالمؤسسة لتطوير نتائج أدائهم كما يتناول قدرة الجامعة على إدارة المـارد البشرية بكفـاءة وفعاليـة لتحقيق التميز في الأداء، حيث أن امتلاك الموارد وحدها لا يضمن التميز في الأداء، ولكن في كيفية تخصيص الموارد وإدارتها من خلال تدريب وتطوير الموارد البشرية لتنميـة مهاراتهم وتحفيزهم لاستخدام تلك المهارات، وثقافتهم المعرفيـة لتحقيق أهداف الجامعة ورفع كفاءة الأداء. (•) وبذلك تتضح أهمية نماذج إدارة التميز في الجامعات بما يسهم في تتمية الموارد البشرية

بها، من خلال النقاط التالية: (1) • تؤدي إلى زيـادة الوعي بأهمية الجودة والاهتمـام بإدارة الجودة ومدى أهميتها في تحقيق الميزة التتافسية بها، وبالتالي ضمان البقاء والاستمرار • 
تثجيع الجامعات على التقييم الذاتي من خـال المعايير التي يقدمها كل نموذج ونقاط

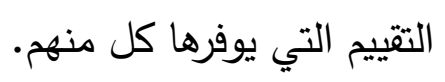

تعمل على التعاون والمشاركة بين الجامعات والمؤسسات المختلفة على نطاق واسع من لهن خـلال نشر المعلومـات التي تتعلق بالتطبيق الناجح لاستراتيجيات الجودة، وبيان الفوائد الناجمة عن تطبيق مثل هذه الاستراتيجيات. زيادة فعالية مشاركة الجامعات في خدمة المجتمع. • دعم ممارسة قياس الأداء (التتييم الذاتي) ومقارنتها بمستويات الأداء العالمية. " زيادة الكفاءة التعليمية، ورفع مستوى أداء العاملين.

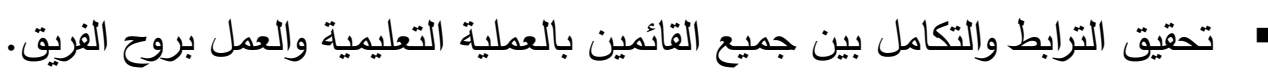

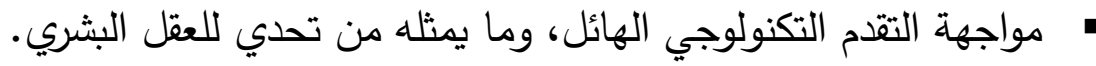

\section{0- التفطيــطالاسـتراتيجـــيـي}

يعرف بأنه عملية تخطيط منطقية تمتاز بتأثيراتها السيكولوجية الفعالة في التأثير على

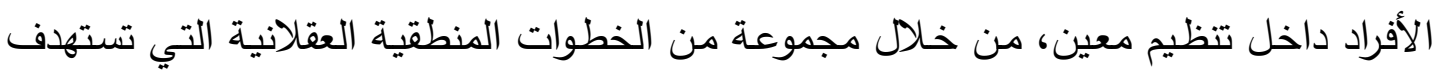
الارتقاء بهذا التنظيم، ويسعى إلى تحقيق أهداف متنوعة منها: تغيير اتجاه المؤسسة التعليمية، والإسـراع بالنمو، وتعظيم العائد، وتركيز الموارد على المهم، وتطوير التتسيق الداخلي بين لهين

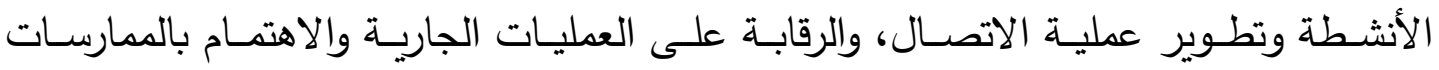
المستمرة، وتدريب الرؤساء، وتتمية ذوي الأداء المتدني، ووضـع القضايا الاستراتيجية في بؤرة

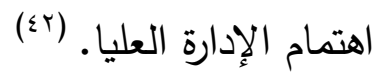
ومن هنا فالحاجة ماسة للتأكيد على دور التخطيط الاستراتيجي الفردي - أي لكل فئات الموارد البشرية بالجامعة - وأهميته للتغلب على الصعوبات التي تعترض التخطيط الاستراتيجي المؤسسي، وتجاوز العقبات التنموية التي تواجه نظام التعليم الجامعي من الناحية الاجتماعية والاقتصادية والتعليمية والإدارية على حد سواء، وذلك ضمانًا لتحقيق الجودة المطلوبة لهذا النوع من التعليم، حيث أن كل فرد في المؤسسة مسئول بصورة فردية عن إدارة جودة ما يخصهـ من العمليات التي تسهم في تقديم النـاتج أو الخدمـة، أي ضـرورة إتقـان كل فرد لأدواره المهنيـة وتطويرهـا باسـتمرار لتحقيـق التنميـة المطلوبـة، حيث يـوفر التخطيط الاسـتراتيجي حلقـات 
المعلومات والتغذيـة المرتدة التي يستهدي بها كل فرد في الجامعـة في تطوير الأداء الراهن إضافة إلى التخطيط للمستقبل. (r)

ويبرز دوره في تتمية الموارد البشرية باعتباره مدخلاً للتخطيط القومي في المرحلة القادمة،

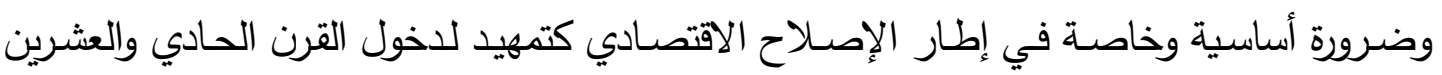

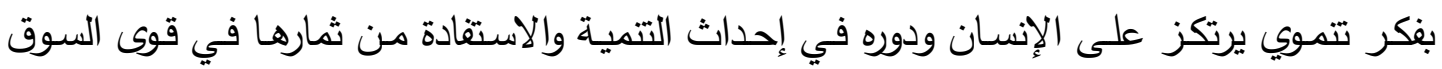

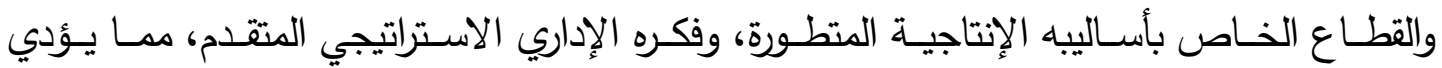

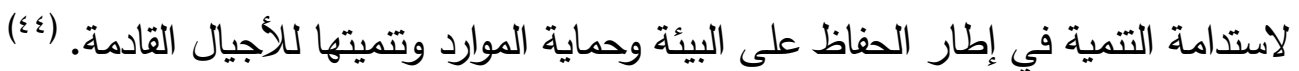

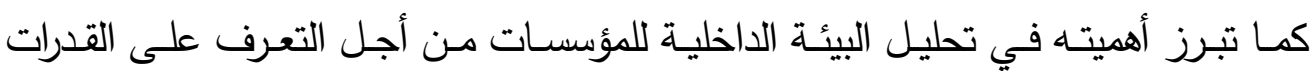
والإمكانـات البشرية المتاحسة بداخلها، ومـا إذا كانت الموارد البشرية بها على مستوى عـال مـن الهن المهارات واستخدام التكنولوجيا الحديثة، وتؤدي العمل بطريقة عالية من الأداء أم لا، وما إذا كانت

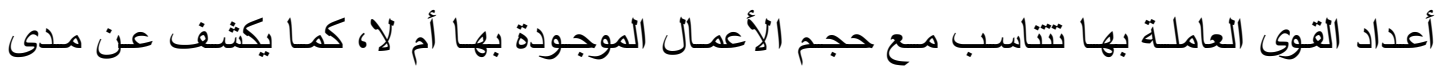

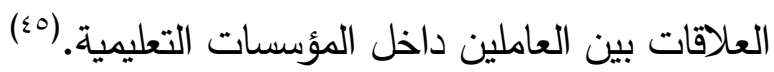
وبذلك يتضح أن التخطيط الإستراتيجي يوفر المعلومات والتغذية المرتدة التي يستهدى التئي بها كل فرد في المؤسسة في تطوير الأداء الراهن إضافة إلى التخطيط للمستقبل، ويسعى أيضاً

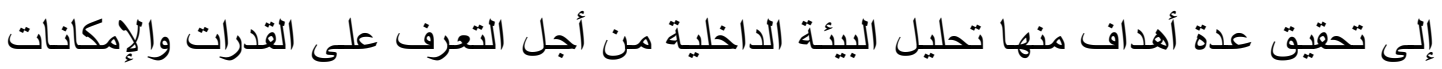
البشرية المتاحة بداخلها، تدريب الرؤساء، وتنمية ذوي الأداء المتدني.

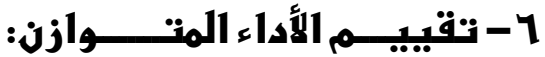

ويعرف بأنه قياس أداء الأفراد والحكم عليه في ضواء الواء الوحدات التنظيمية والأقسام التي

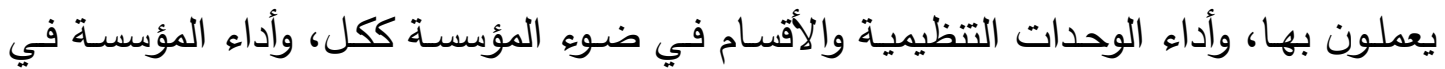

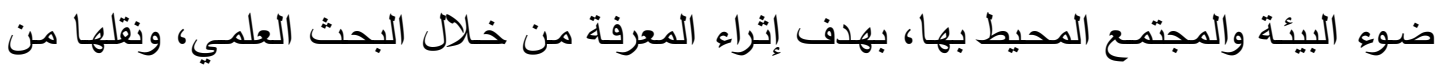

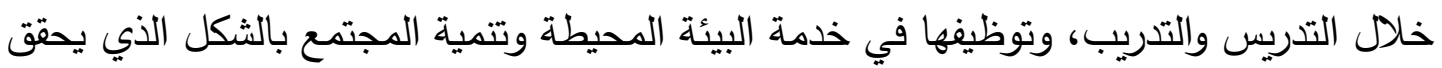

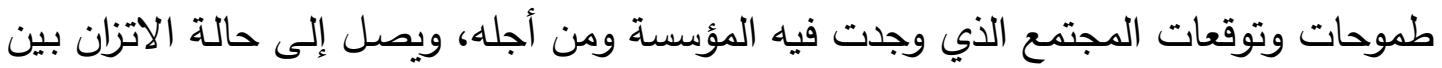
مكوناتها والمحافظة عليها، بإعطاء الوزن والقيمة المناسبة لكل بعد من أبعاد الأداء والمتمثلة

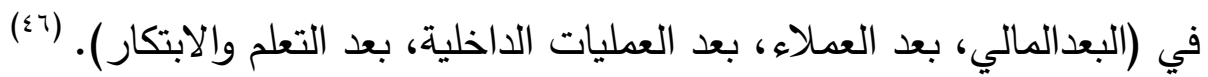

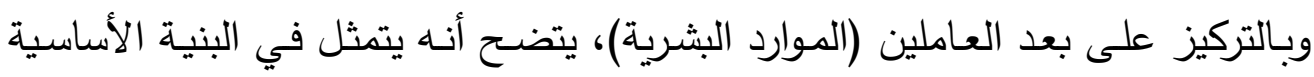

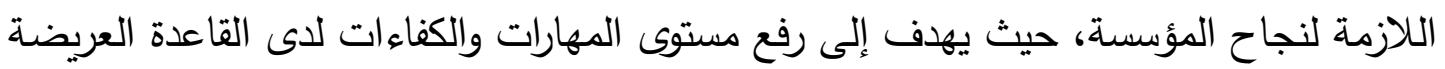




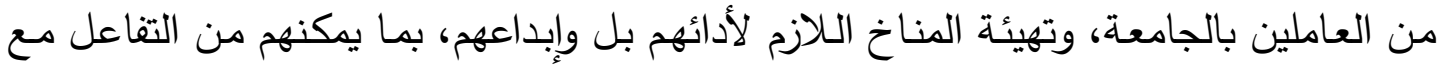

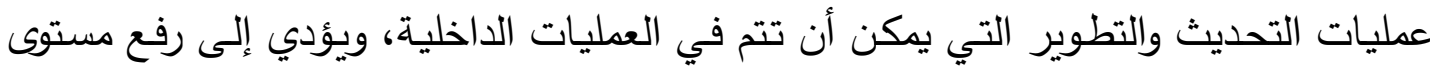

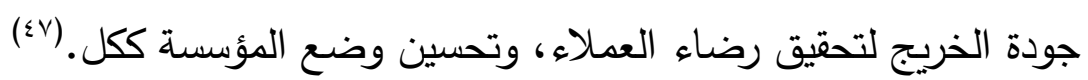

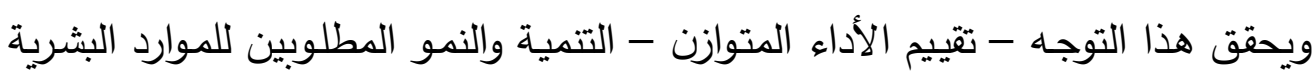

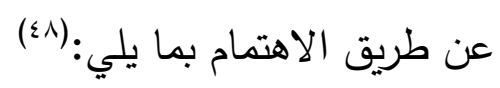

تتمية قدرات العاملين التي تمكنهم من أداء أدوارهم عن طريق تأهيلهم وتتمية مهاراتهح وقدراتهم التتظيمية التي تستطيع إنجاز الأهداف التنظيمية خاصة عندما يحدث تحول في الهيكل التنظيمي للمؤسسة وأهدافها وطرق عملها.

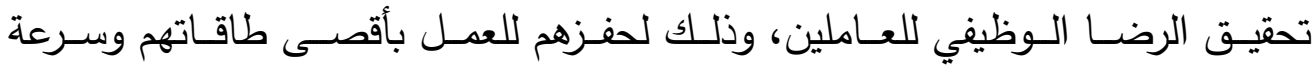
استجاباتهم لأداء المهام المطلوبة منهم بما يؤدي إلى زيادة إنتاجية الجامعة. الاحتفاظ بالعاملين بالمؤسسة خاصة الأكفاء منهم.

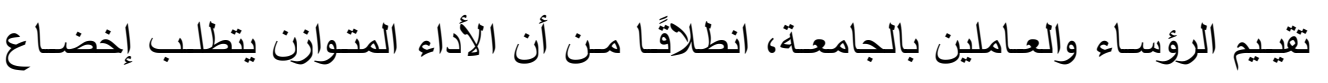

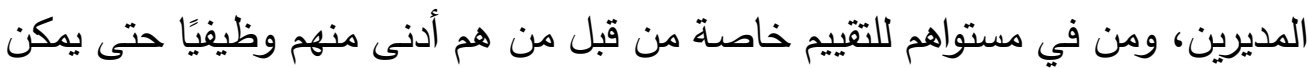
الوقوف على جدواهم وفعاليتهم وكفاءتهم في تصريف الأمور وإدارة الغير . هياس إنتاجية العناصر البشرية من العاملين وأعضاء هيئة التدريس.

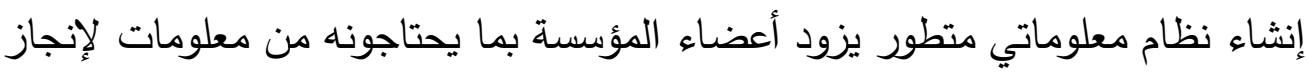
أعمالهم، وتحقيق الأهداف المنشودة. ت تهيئة مناخ ملائم للإبداع والمبادأة تسوده الحرية والعدالة والمحاسبية على الأداء.

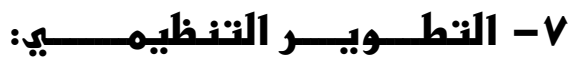

يعد صيغة من صيخ التغير التنظيمي ومدخلاً سلوكيًا لتيسير التغير في قيم ومعتقدات ومدركات واتجاهـات وقدرات وسلوكيات العـاملين فرادى وجماعـات وفي ممارستهم لأدوارهم

ومهامهم التظيمية. (9 §

\section{كما يعرف التطوير التظيمي بأنه:(0)}

هـ التغير المنشود الذي يتضمن المؤسسة بالكامل، ويستهدف زيادة الفاعلية المؤسسية.

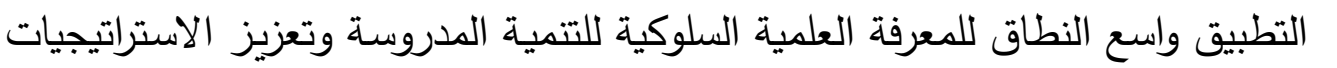
المؤسسية والبنية والعمليات من أجل تحسين فاعلية المؤسسة. 
نشـاط نظامي وعمليـة مستمرة تسـاعد المؤسسـة على التعامل مـع المشكلات الحالية والمتوقعة، ووضع القادة في موقف استباقي وليس ارتكاسي. ويعرف أيضاً بأنه استراتيجية تعليمية، تهاف إلى إنى

تغير الاتجاهات والاعتقادات والقيم والهياكل التنظيمية لأفراد المؤسسة، من أجل التأقلم

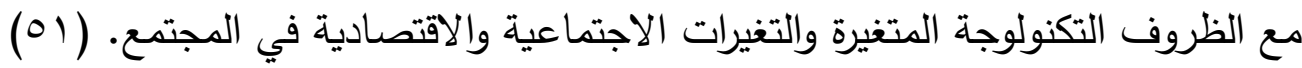
تتمية روح الجماعة من خلال زيادة درجة الإحساس بتفاعل وديناميكية الجماعة داخل

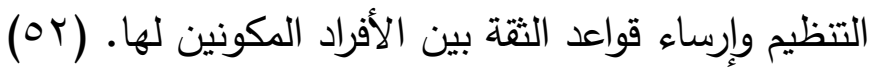

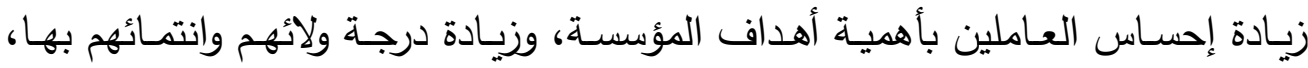
وتعويدهم على ممارسة الرقابة الذاتية والتوجيه الذاتي داخلها. تطوير وتتمية وتعديل ثقافة المؤسسة والتي تتمثل في مجموعة القيم والمبادئ والتقاليد التي تحكم سلوك الأفراد والجماعات وتتظيم علاقاتهم ومعاملاتهم.

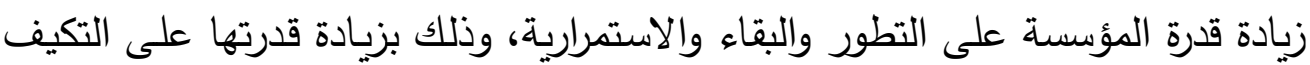
مع البيئة المتغيرة مما يجعل منها نظامًا متجددًا.

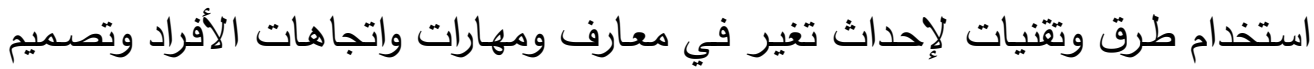

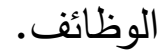

توفير نوع من الاستثارة (المستثار الداخلي أو الخارجي) أو وكلاء التغير والتي تثجع الأفراد على تعاون كل منهم مع الآخر لحل المشكلات. وتتبع أهميته للمؤسسة من خلال تحقيقه ما يلي:

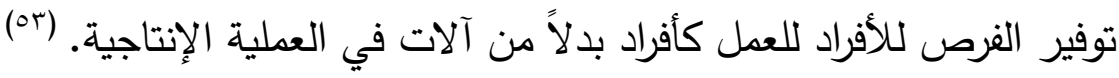
توفير الفرصة لكل فرد في المؤسسة لتطوير الحد الأقصى من قدراته. يسعى إلى زيادة فاعلية المؤسسة من حيث تحقيق كافة أهدافها. هيعى إلى تهيئة البيئة التي من خلالها يمكن التوصل إلى بيئة عمل مثيرة.

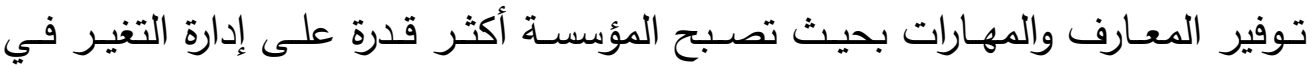

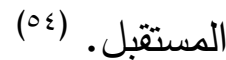
مساعدة المؤسسة على تغير نفسها، فضلاً عن تقييم نفسها وبيئتها وتتشيط وإعادة بناء استراتيجيات وبنياتها وعملياتها. 
مساعدة أفراد المؤسسة على اكتساب المهارات والمعارف اللازمة لإجراء تحسين مستمر

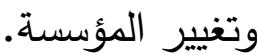
هساعدة المؤسسة بالكامل بحيث تصبح أكثر إبداعية وفاعلية وأكثر قدرة على التكيف. توفير المهارات والمعارف الضرورية لتشييد العلاقات الثخصية الفعالة وبناء فرق منتجة.

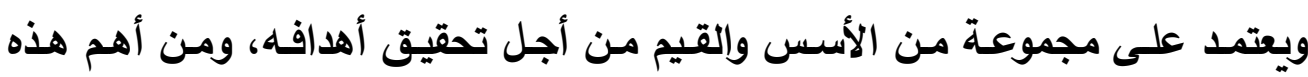
الأسس ما يلي:(00)

المشاركة: من خلال بيئة صحيحة تدعم المشاركة، تستطيع معظم المؤسسات أن تبني موقع عمل ناجح بحيث يشعر العاملون بالانخراط في العمل.

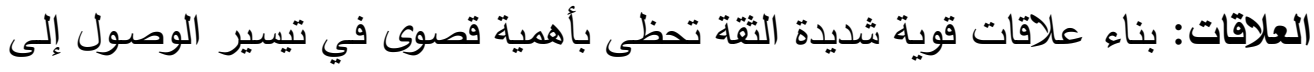

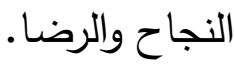
الموثوقية: النظم التي تطور وتعزز الموثوقية من خلال التواصل المفتوح والصحيح

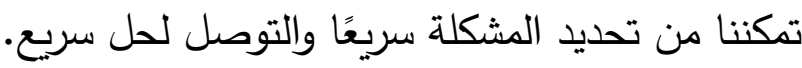

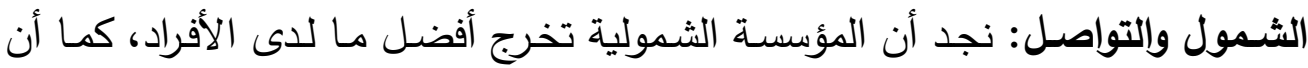
عمليات التواصل تسمح بالتعاون والمشاركة.

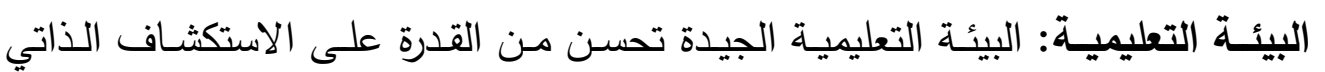
والوعي بالذات، وتتاقش مواطن القوى والضـف بين العاملين، وتقدم لهم الدعم عند الدان تطوير وصياغة مهارات جديدة. الاحترام: حيث يضيف كل عضو من أعضـاء المؤسسة إلى قيمها من خلال احترام بعضهم البعض خلال العمل واتخاذ القرارات. التمكين: التقسيم الملائم للعمل وتمكين العاملين يضمن قدرة المؤسسة على تحقيق

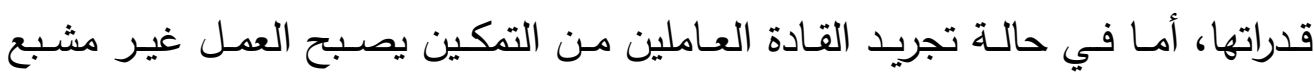
والأدوار غير فعالة. المرونـة: تسمح المرونـة بالمزيدـ من التعاونية والإبداعية، واغتتـام العديد من الفرص والحلول المحتملة لمواجهة المشكلات. الاستباقية: يكون عمل التطوير التظظيمي أكثر فاعلية عندما يكون استباقي وليس ارتكاسي، حيث أنه يسعى إلى دعم المؤسسة اليوم وغدًا. 
وبذلك يتضح من العرض السابق أن التطوير التظيمي يعد استراتيجية متكاملة تهدف إلى تطوير المؤسسة ككل، وزيـادة فاعليتها، كما يسعى إلى تغيير الاتجاهـات والقيم والهياكل التنظيمية والممارسات الإداريـة لتحسين الأداء التتظيمي، ويوفر الفرصـة لكل فرد في المؤسسـة لتطوير الحد القصسى من قدراته، كما يساعد على اكتساب المهارات والمعارف اللازمـة لإجراء تحسين مستمر وتغيير المؤسسة، ويساعد المؤسسة بالكامل لكي تصبح أكثر إبداعية وفاعلية وأكثر قدرة على التكيف.

\section{ثالثاً : الإجراءات المقترحة لتنمية الموارد البشرية في ضوي الإتجاهات الحديثة :}

بدء برنامج قوي للتثقيف والتحسين الذاتي لكل فرد. الاهتمام بالتدريب المستمر على رأس العمل. تخفيض المعوقات والحدود بين الأقسام الوظيفية لبناء فرق العمل. الاشتراك في عضوية المؤسسات التربوية والعلمية على المستوى الإقليمي والعالمي، مما يثجع المساهمة والتعاون في تطوير التعليم الجامعي. تثجيع الأعمال البحثية والتطويريـة وتعزيز الثقـة في البحث العلمي الجامعي ودعمـه معنويًا وماديًا .

استحداث نظم اتصال فعالة بين الجامعات المختلفة بعضها وبعض وبينها وبين مراكز البحوث بما يضمن التكامل وعدم التكرار للموضوعات.

تبني ثقافـة تنظيميـة بالجامعـة تشـع أعضـائها في جميع التخصصـات على مشـاركة المعرفة وتبادلها بشكل فعال، وتكافئ من يملكها.

عقد اللقاءات والمؤتمرات والندوات العلمية وغيرها، حيث تمثل هذه الروافد آليات لنقل وتبادل وتطوير المعرفة داخل الجامعة وخارجها بالثكل الذي يسهم في تتمية مواردها البشرية، وتحقيق تميزاً في أدائهم البحثي والعملي. تطوير نظم النشر الإكتروني لتيسير إجراءات النشر العلمي في المجالات والدوريات المحلية والعالمية. 


\section{مسراجه البحث}

(1) جمـال أبو الوفا: "توجهات إدارة الجامعـة المصـرية نحو تتميـة مواردهـا البشـرية لمواجهـة التحديات المحلية والعالمية (رؤية نقدية وإطلاله مستقبلية)"، المؤتمر العلمي السنوي التاسع

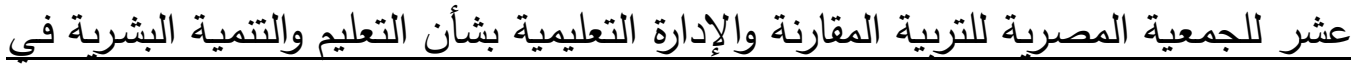

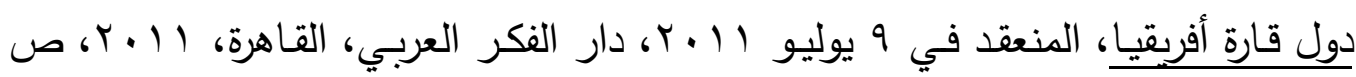
$.1 \leqslant 0$

(Y) أحمد حسين الصـغير : "بعض مشكلات أعضـاء هيئة التدريس التي تؤثر على أدائهم

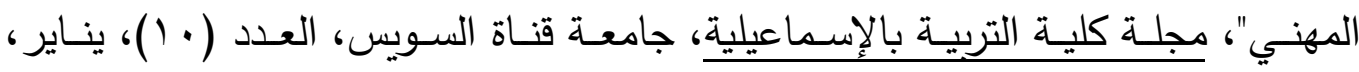

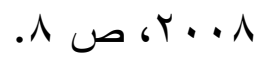

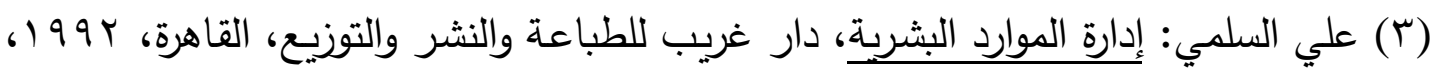
ص ص مان

(§) حبيب الصحاف: معجم إدارة الموارد البشرية وشئون العاملين (عربي - انجليزي)، مكتبة

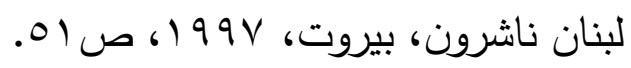

(0) حسام الدين جاد الرب: معجم مصطلحات التتمية البشرية، روافد للنشر والتوزيع، القاهرة، . Ar ص ص 111

(6)Muhammad Tariq, Naseer Ahmed and Khalid Mahmad, "An Organizational Concept of Human Resource Development - How Human Resource Management Scholars View, HRD", Far East Journal of Psychology and Business, vol. (8), No.(3), Sep., 2012, P.51.

مانع سبرينة: أثر إستراتيجية تنمية الموارد البشرية على أداء الأفراد في الجامعات: دراسة (2) حالة: عينة من الجامعات الجزائريـة، رسالة دكتوراه غير منشورة، قسم علوم التسيير، كلية

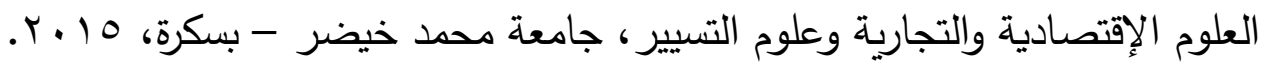

(8) S. Mufeed Ahmed and Ajaz Akbar Mir, "Need for Human Resource Development (H R D) Practices in India universities: A key for Educational Excellence", Journal of Human Values, Vol. (18), No. (2), 2012.

(9) بارك نعيمة: "تتمية الموارد البشرية وأهميتها في تحسين الإنتاجية وتحقيق الميزة التتافسية"،

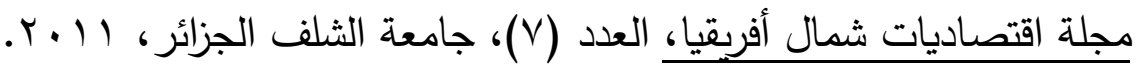

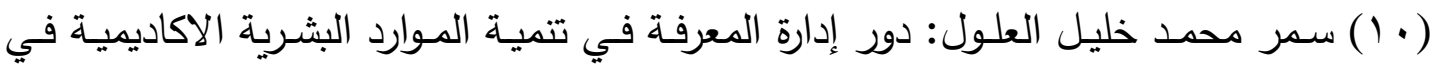
الجامعات الفلسطينية بقطاع غزة، رسالة ماجيستير غير منشورة، قسم أصول التربية، كلية

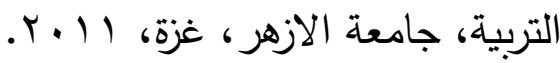


(1 (1) عاصم شحاده علي: "تنمية الموارد البشرية في ضوء تطبيق مبادئ إدارة الجودة الثاملة

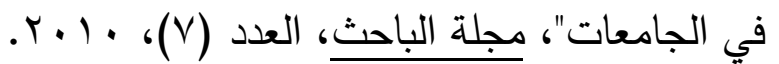

(Y ( ) عبدالرحيم محمد عبدالرحيم، "التنميـة البشـرية ومقومـات تحقيق التنميـة المسـتدامة في

الـوطن العربـي"، المؤتمر العربـي السـادس لـلإدارة البيئة: التنميـة البشـربة وآثارهـا علىي

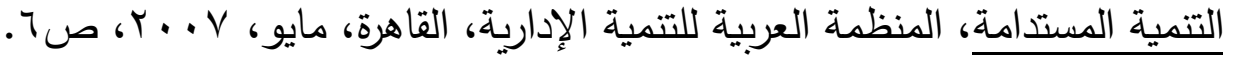

(13) Jon M. Werner and Randy L. Desimone, Human Resource

Development,sixth edition, Erin Joyner Publisher, Canada, 2012, P.4.

(14) Sanjcev Kumar Singh, Human Resource Development, ATLANTIC

Publishers, Delhi, India, 2008, P.6.

(0 1 ) حافظ فرج أحمد: "التتميـة المهنية المستدامة لأستاذ الجامعـة في ضـوه متغيرات العصـر"،

المـؤتمر القـومي السـنوى الحـادي عشـر (العربـي الثالـث): التعلـيم الجـامعي العربـي: آفـاق

الاصـلاح والتطوير، مركز تطوير التعليم الجامعي بالتعاون مـع مركز الدراسـات المعرفيـة،

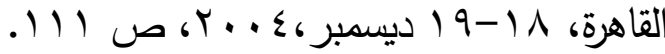

(7 (1) محمد حسن محمد حمادات: الإدارة التربوبة: وظائف وقضايا معاصرة، دار الحامد للنشر

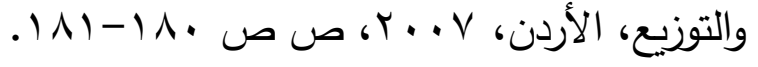

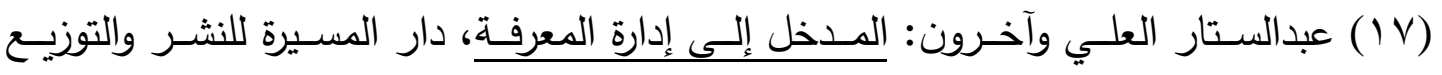

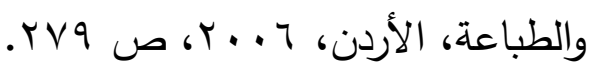

(18) Sanjcev Kumar singh, "Human Resource Development", Op.Cit., P. 69.

(19) Look at:

- Ibid, PP. 69-70.

- S. Mufeed Ahmed and Ajaz Akbar mir, "Need for Human Resource Development (HRD) Practices in India universities: Aky for Education Excellence". Op.Cit, P.123.

(20) Michael Armstrong: Strategic Human Resource Management: A Guide to Action, 3RD Edition, Theomson- Shore, Inc., United States, 2006, PP. 134-135.

(21) Ibid, P.135.

(Y) محمد عبد الفتاح شـاهين: "التطور المهني لأعضـاء الهيئات التدريسية كمدخل لتحقيق

جودة النوعية في التعليم الجـامعي"، مؤتمر النوعيـة في التعليم الجـامعي الفليسطيني:

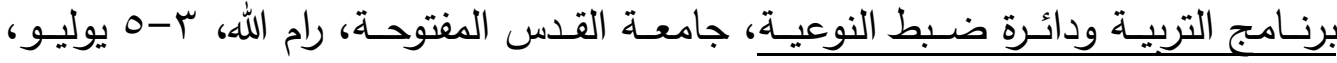

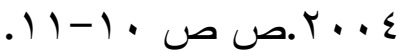

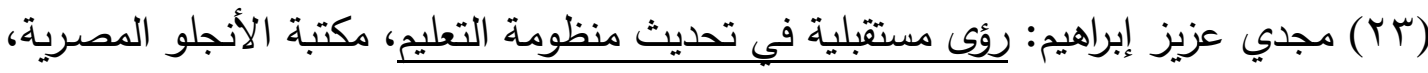

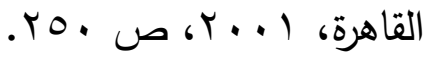




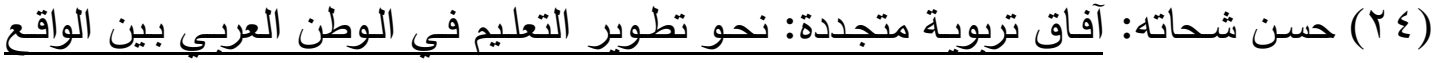

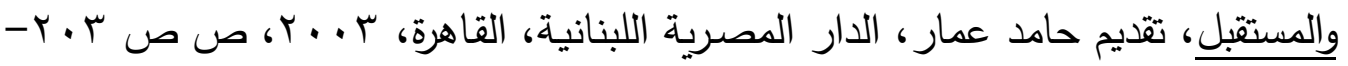

$$
\text { .r. } \varepsilon
$$

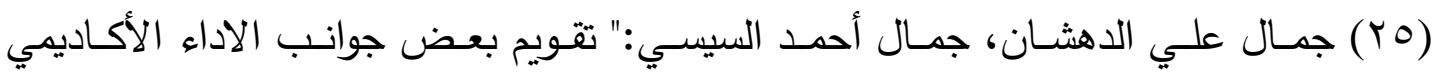

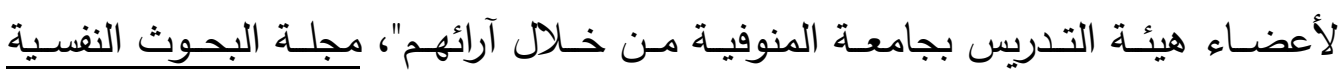

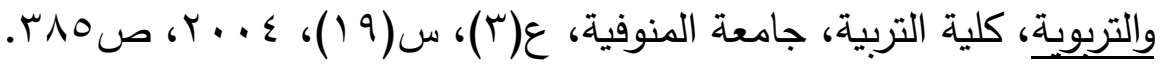

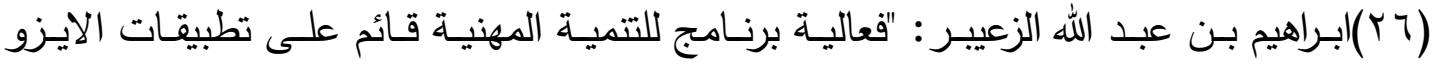
بالمؤسسات التعليمية في تحسين جودة الحياة الوظيفية لدى أعضاء هيئة التدريس بجامعة العائة

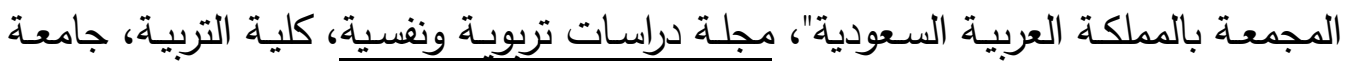

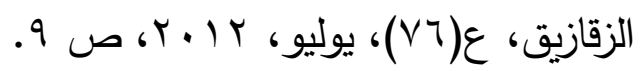

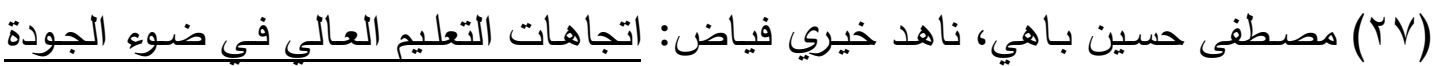

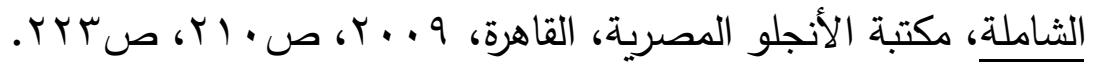

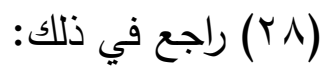

سيد محمد جاد الرب: الاتجاهات الحديثة في إدارة الموارد البشرية، (د.ن)، 9 . . ب؟،

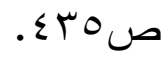

محسن عبد الستار محمود عزب: تطوير الإدارة المدرسية في ضوه معايير الجودة

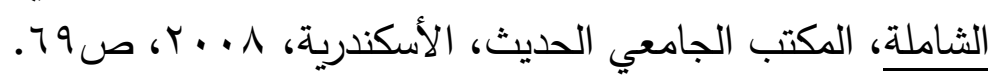

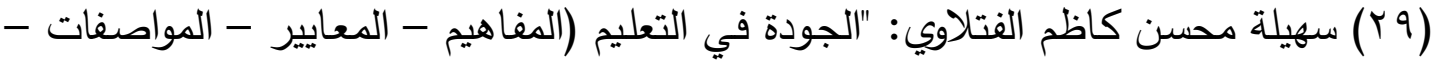
المسئوليات)"، سلسلة طرائق التدربس، الكتاب الثامن، دار الثروق للنشر والتوزيع،

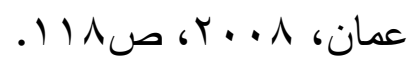

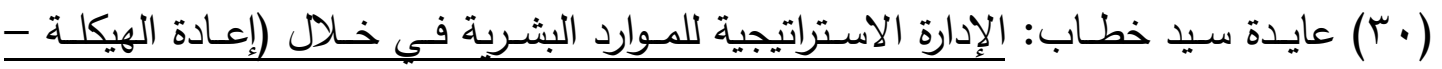

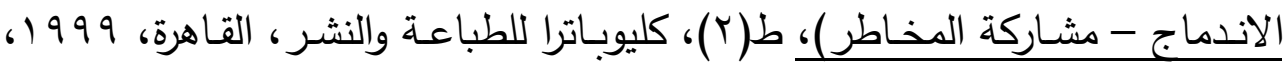

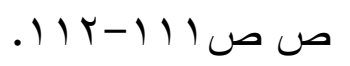

(31) Bret M. Benjamin and et. al, "Organizational Change Models In Human Resource Development", World Journal Franklin Publishing Company, No. (2), 2012, PP. 6-7.

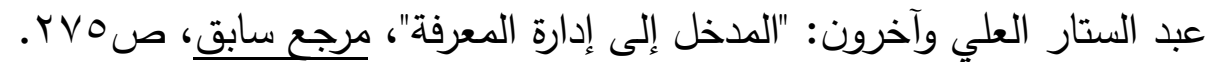

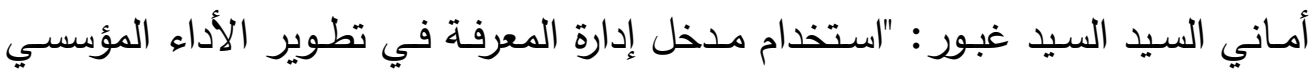

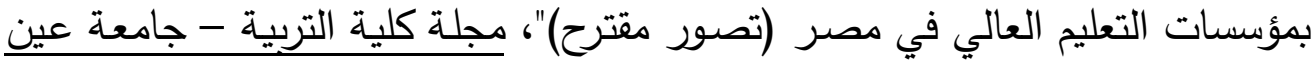

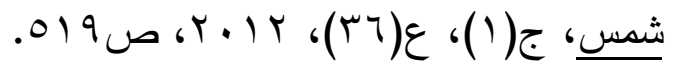




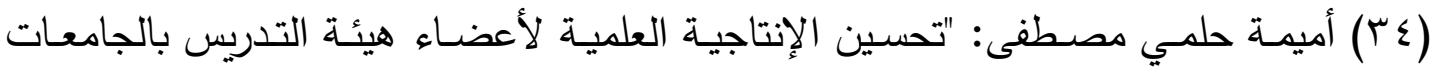

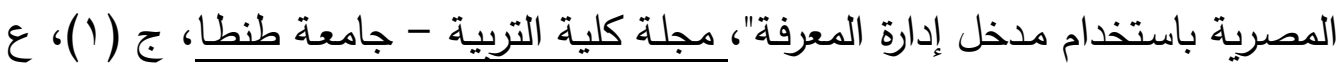

$$
\text { . }
$$

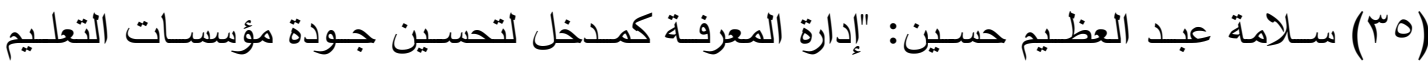

الجامعي (رؤيسة مستقبلية)"، المؤتمر السنوي الأول: مستتبل التعلم الجامعي العري رؤى إنى تتموية أبحاث علمية وفعاليات أكاديمية، ج(ب)، المركز العربي للتعليم والتتمية بالتعاون

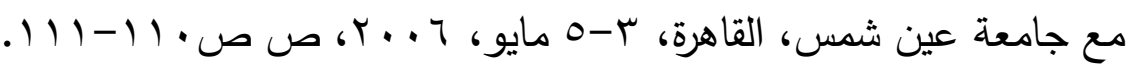

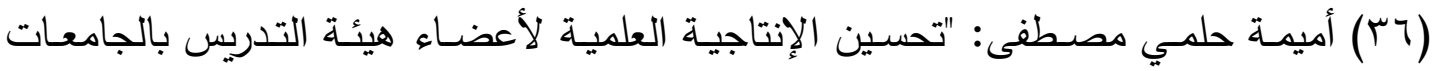

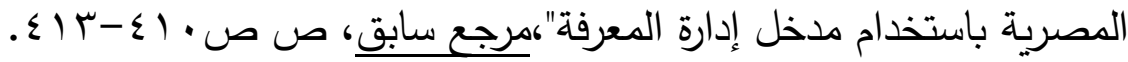

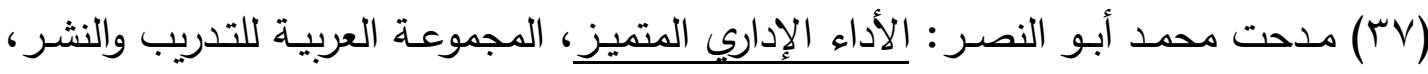

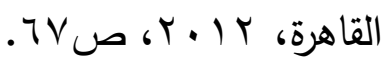

(^^) منى أحمد محمد حمودة: "إطار مقترح لتطبيق إدارة التميز لرفع كفاءة الأداء بالجامعات"، مجلـة البحوث المالية والتجاريـة، كلية التجارة ببور سعيد، جامعة قناة السوي، ج(r)،

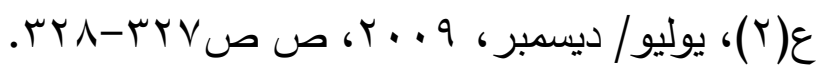

(q) عبـد العزيـز علـي حسـن: الإدارة المتميـزة للمـوارد البشـربة: تميـز بـلا حـدود، المكتبـة

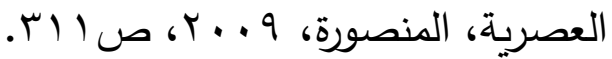

( • ) منى أحمد محمد حمودة: إطار مقترح لتطبيق إدارة التميز لرفع كفاءة الأداء بالجامعات،

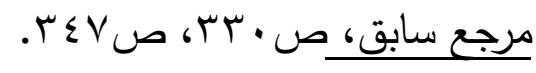

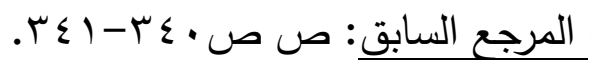

(乏Y) حسن شحاتة: آفاق تربوبية متجددة: مداخل إلى تعليم المستقبل في الوطن العربي، تقديم

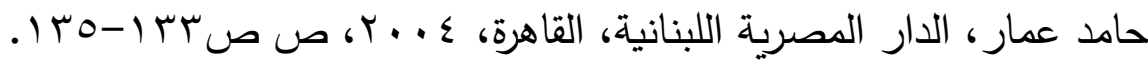

( ) أسامة محمود زيدان: "تفعيل دور عضو هيئة التدريس في التخطيط الاستراتيجي لتحسين

جودة الأداء بالجامعات"، المجلة الدولية للأبحاث التربوبـة، كلية التربية، جامعة الإمارات

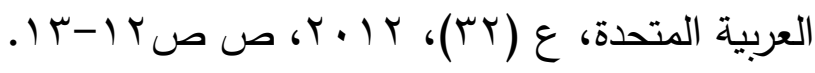

(乏) سمر عبد الوهاب الخويت: "التخطيط الاستراتيجي للتعليم الفني وتنمية الموارد البشرية"،

المؤتمر العلمي العاشر : التعليم الفني والتدربب - الواقع والمستقبل، كلية التربية، جامعة

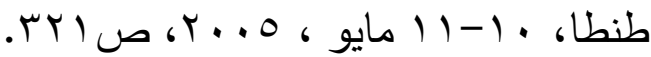




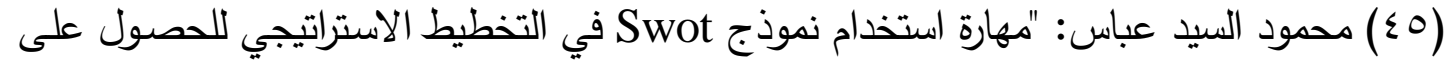

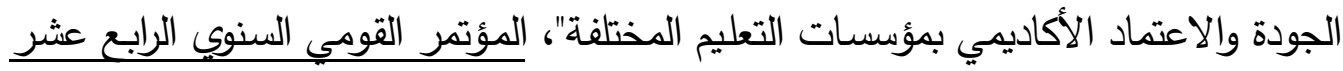

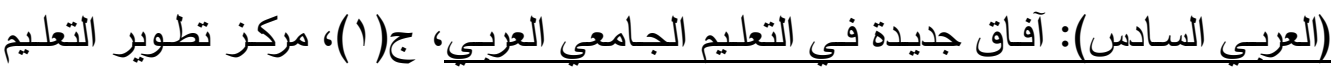

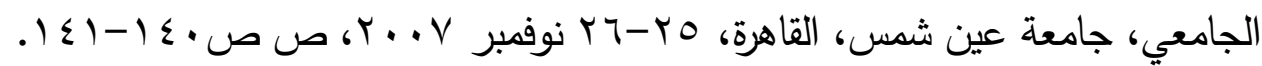

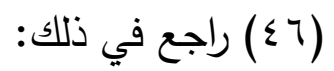

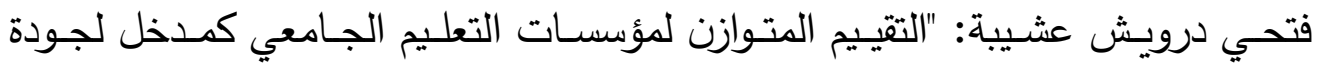

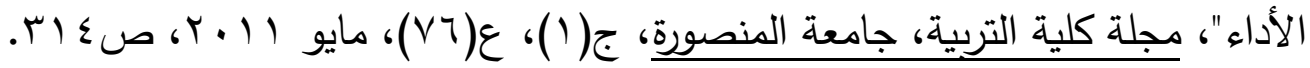

- Charles Tennant and et.al., "The Design of A training Programe

Measurement Moddel", Journal of European Industrial Training,

$$
\text { Vol.(26), No.(5), 2002, pp. 231-232. }
$$

ف (乏V)

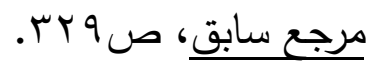

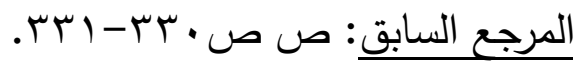

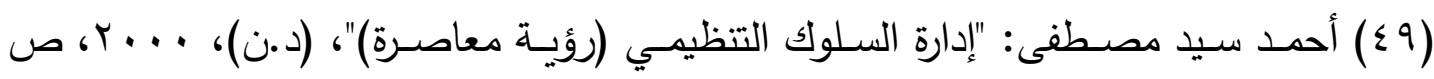

$$
\text { ص ص }
$$

(50) Diane E. Talman and et.al., Organizational Chang and Development, Adult Education Perpectives forJudicial Education, Georgia Center for Continuing Education, University of Georgia, 1992, P. 1211.

(51) Shivangee S. and pankaj K.D., "Employee Invlovement An Approach to Organizational Development \& change", VSRD International Journal of Business \& Management Resarchy, Vol. (1), No. (8), 2011, P. 556.

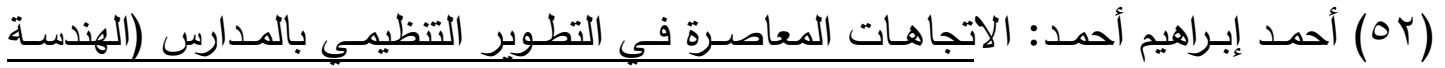

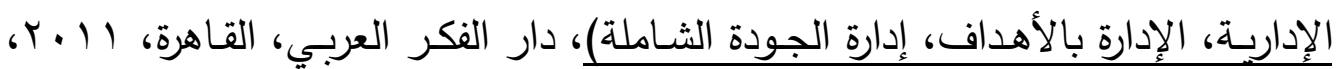

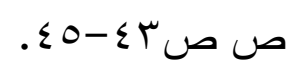

(53) Donald L. Anderson, Organization Development: The Process of Leading Organizational Change, Second Edition, SAGE publication Inc, London, 2012, p. 40.

(54) Thomas G. Gummings and Christopher G. Worley, Organization Development \& Change, 10th Edition, Neison Education Ltd, United State of America, 2013, pp. 6-7.

(55) Lisa Haneberg, Organization Development Basics, second printing, American Society for Training \& Development Press, United State of America, 2005, p. 4. 